This item was submitted to Loughborough's Research Repository by the author.

Items in Figshare are protected by copyright, with all rights reserved, unless otherwise indicated.

\title{
Research students and the Loughborough institutional repository
}

PLEASE CITE THE PUBLISHED VERSION

LICENCE

CC BY-NC-ND 4.0

\section{REPOSITORY RECORD}

Pickton, Margaret J.. 2019. "Research Students and the Loughborough Institutional Repository". figshare. https://hdl.handle.net/2134/571. 


\section{Certificate of Originality}

This is to certify that I am responsible for the work submitted in this dissertation, that the original work is my own except as specified in acknowledgements, footnotes or references, and that neither the dissertation or the original work contained therein has been submitted to this or any other institution for a degree.

Signed

Date 


\section{Research students and the Loughborough institutional repository}

by

Margaret J. Pickton PhD, BA

A Master's Dissertation, submitted in partial fulfilment of the requirements for the award of Master of Science degree of Loughborough University.

September 2005

Supervisor: Professor Cliff McKnight, PhD, AFBPS, FBCS

Department of Information Science

(C) M.J.Pickton, 2005 


\begin{abstract}
This dissertation investigated the potential role for research students in a new institutional repository at Loughborough University.

The project began with an extensive search for information concerning stakeholders' attitudes towards open access publishing and institutional repositories. It was apparent from this review that no previous research had focused on the needs and potential contribution of research students in this area.
\end{abstract}

Two studies were therefore carried out. The first, an email survey of managers of existing institutional repositories, investigated student use of their repositories, advocacy undertaken, and attitudes toward research student content. Responses were received from 35 universities in the UK and abroad. The second study comprised face-to-face interviews with 34 research students at Loughborough University. Using a mixture of closed and open questions, the interviews explored the students' experiences and opinions of publishing, open access and the proposed Loughborough repository.

Repository managers were overwhelmingly in favour of permitting the deposit of research student work, albeit under specified conditions. One half of the respondents mentioned allowing, or even encouraging, the deposit of theses and dissertations. The relative newness of many repositories meant that advocacy to student authors was limited, although a number of managers were including the repository in routine research training sessions.

The interviews with research students established that, as readers, they wanted to find many more types of material in the repository than, as authors, they were willing to deposit. However, complete theses, postprints and conference papers were acceptable to both groups. The ability to disseminate their work and receive feedback and commentary were the most important motivators to students depositing work, closely followed by the principle of open access. The greatest deterrents were the risk of being unable to publish elsewhere later, the ownership of copyright, and plagiarism.

Based on the findings of the literature review and the two studies, appropriate recommendations were made for the Loughborough repository. 


\section{Acknowledgements}

My thanks go to the research students who were so willing to give up their time to help me; to the repository managers who delighted me by taking my questions seriously, and then answering with such care; to my supervisor, Professor Cliff McKnight, for his advice and sense of humour; and to my family, Dave, Anna and Michael, who have had to learn more about institutional repositories than they ever expected.

Thanks to you all.

Miggie Pickton 


\section{Contents}

$\begin{array}{lr}\text { Abstract } & \text { ii } \\ \text { Acknowledgements } & \text { iii } \\ \text { Contents } & \text { iv } \\ \text { List of Figures } & \text { ix } \\ \text { List of tables } & \text { x }\end{array}$

$\begin{array}{lll}\text { Chapter } 1 & \text { Institutional repositories and scholarly publishing } & 1\end{array}$

1.1 Introduction 1

1.2 Open access - definition 1

1.3 Drivers of open access publishing 2

1.4 Resistance to open access publishing 3

1.5 Institutional repositories: definition and description 4

1.6 Aims and objectives 5

Chapter 2 Users' attitudes towards IRs: a review of the literature 6

2.1 Introduction 6

2.2 Institutional repositories: benefits to institutions 6

2.2.1 Raising the institutional profile 6

$\begin{array}{lll}2.2 .2 & \text { Total intellectual output } & 7\end{array}$

$\begin{array}{lll}2.2 .3 & \text { Teaching and learning } & 7\end{array}$

$\begin{array}{lll}\text { 2.2.4 Leverage of existing investment in information systems } & 7\end{array}$

2.2.5 Supporting institutional record keeping 8

2.2.6 Cost savings 8

2.3 Institutional repositories: benefits to users 8

2.3.1 Dissemination and impact 8

2.3.2 IR content 9

2.3.3 Feedback and commentary 9

2.3.4 Added value services 9

$\begin{array}{ll}\text { 2.3.5 Networked information } & 10\end{array}$

$\begin{array}{lll}2.4 & \text { Institutional repositories: issues and concerns }\end{array}$

2.4.1 Cultural change 11

$\begin{array}{lll}2.4 .2 \text { Cost } & 11\end{array}$

$\begin{array}{lll}2.4 .3 & \text { Sustaining support and commitment } & 12\end{array}$ 
$\begin{array}{lll}2.4 .4 & \text { Technology } & 12\end{array}$

$\begin{array}{lll}2.4 .5 & \text { Preservation } & 12\end{array}$

2.4.6 Power and control 12

$\begin{array}{lll}2.4 .7 & \text { Policy } & 13\end{array}$

$\begin{array}{lll}2.4 .8 & \text { Rights management } & 13\end{array}$

$\begin{array}{lll}2.4 .9 \quad \text { Versioning } & 14\end{array}$

$\begin{array}{lll}2.5 & \text { Author attitudes to OA publishing } & 14\end{array}$

$\begin{array}{lll}2.5 .1 & \text { Principle of open access } & 14\end{array}$

2.5.2 Awareness 14

2.5.3 Accessibility and impact 15

$\begin{array}{lll}2.5 .4 & \text { Author fees } & 15\end{array}$

$\begin{array}{lll}2.5 .5 & \text { Additional services } & 16\end{array}$

$\begin{array}{lll}2.5 .6 & \text { Quality } & 16\end{array}$

$\begin{array}{lll}2.5 .7 & \text { Rights } & 16\end{array}$

$\begin{array}{lll}2.5 .8 & \text { Practical issues } & 17\end{array}$

$\begin{array}{lll}2.5 .9 & \text { Authors as readers } & 17\end{array}$

$\begin{array}{lll}2.6 & \text { Author attitudes: areas for further investigation } & 18\end{array}$

$\begin{array}{lll}\text { Chapter } 3 & \text { Research methodology } & 19\end{array}$

$\begin{array}{lll}3.1 & 19\end{array}$

$\begin{array}{lll}3.2 & \text { Literature Review }\end{array}$

$\begin{array}{lll}3.2 .1 & \text { Sources } & 19\end{array}$

$\begin{array}{lll}3.2 .2 & \text { Search terms } & 19\end{array}$

$\begin{array}{lll}3.3 & \text { Repository managers' survey } & 21\end{array}$

3.3.1 Choice of method - the email survey 21

3.3.2 Design of the email survey 21

$\begin{array}{lll}\text { 3.3.3 Pilot study } & 21\end{array}$

3.3.4 Selection of respondents 22

3.3.5 Data analysis 23

$\begin{array}{lll}3.4 & \text { Research student interviews } & 23\end{array}$

3.4.1 Choice of method - the face to face interview 23

3.4.2 Design of the interview schedule 24

$\begin{array}{lll}3.4 .3 & \text { Pilot study } & 26\end{array}$

3.4.4 Selection of participants 28

$\begin{array}{lll}3.4 .5 & \text { Data analysis } & 30\end{array}$

$\begin{array}{lll}3.5 & \text { Ethical issues } & 30\end{array}$ 
Chapter 4 Institutional repository managers - survey results

4.1 Introduction 32

4.2 Use of the repository by research students 32

4.2.1 Amount of use 32

4.2.2 Evidence for use 33

4.2.3 Type of material deposited 34

4.2.4 Other comments 35

4.3 Promoting the repository to research students 36

4.3.1 Is the repository promoted? 37

$\begin{array}{lll}\text { 4.3.2 To whom is the repository promoted? } & 37\end{array}$

$\begin{array}{lll}4.3 .3 & \text { Means of promotion } & 37\end{array}$

$\begin{array}{lll}\text { 4.3.4 Other comments } & 38\end{array}$

4.4 The repository as a place for research student output 38

$\begin{array}{lll}4.4 .1 & \text { Deposit without conditions } & 39\end{array}$

$\begin{array}{lll}4.4 .2 & \text { Deposit with conditions } & 40\end{array}$

4.4.3 Other comments 41

$\begin{array}{lll}4.5 & \text { Conclusion } & 41\end{array}$

Chapter $5 \quad$ Research student interviews - results 42

5.1 Introduction 42

5.2 Information seeking and publishing 42

5.2.1 Sources of information 42

5.2.2 Publishing history 43

5.2.3 Reasons for publishing 44

$\begin{array}{lll}5.3 & \text { Open access publishing } & 47\end{array}$

$\begin{array}{lll}\text { 5.3.1 The OA movement } & 47\end{array}$

$\begin{array}{lll}5.3 .2 & \text { The serials crisis } & 48\end{array}$

$\begin{array}{lll}\text { 5.3.3 Digital repositories } & 48\end{array}$

5.3.4 The Loughborough repository 49

5.4 The Loughborough repository: practicalities 49

5.4.1 Type of work to be deposited 49

5.4.2 File formats 52

5.4.3 The research student as reader 53

5.4.4 Responsibility for tasks $\quad 55$

5.4.5 Mandating deposit 58

$\begin{array}{lll}5.5 & \text { Attitudes toward depositing } & 60\end{array}$

$\begin{array}{lll}5.5 .1 & \text { Motivations } & 60\end{array}$ 
$\begin{array}{lll}\text { 5.5.2 Deterrents } & 62\end{array}$

5.6 The decision to deposit 64

$\begin{array}{lll}5.7 & \text { Conclusion } & 64\end{array}$

Chapter 6 Research students and institutional repositories discussion $\quad 65$

6.1 Introduction 65

6.2 Research students as authors: reasons for and against depositing work in an IR 65

6.2.1 Accessibility and impact 65

$\begin{array}{lll}6.2 .2 & \text { Rights } & 66\end{array}$

$\begin{array}{lll}6.2 .3 & \text { The principle of open access } & 67\end{array}$

6.2.4 Influence of other people 68

$\begin{array}{lll}6.2 .5 & \text { Quality } & 68\end{array}$

6.2.6 Assistance with use 69

$\begin{array}{lll}6.2 .7 & \text { Additional services } & 69\end{array}$

$\begin{array}{ll}\text { 6.2.8 Longer term issues } & 70\end{array}$

6.2.9 Effect on others 70

$\begin{array}{lll}6.3 & \text { Research students as readers } & 71\end{array}$

$\begin{array}{lll}\text { 6.3.1 Electronic theses } & 71\end{array}$

6.3.2 Other types of material 72

6.4 Research student use of the IR: management issues 72

$\begin{array}{lll}6.4 .1 & \text { Policy } & 72\end{array}$

$\begin{array}{lll}6.4 .2 & \text { Repository organisation } & 73\end{array}$

$\begin{array}{lll}6.4 .3 & \text { Quality } & 73\end{array}$

$\begin{array}{lll}\text { 6.4.4 Single or multiple repositories } & 74\end{array}$

6.4.5 OAl Harvesting 75

$\begin{array}{lll}6.5 & \text { Conclusion } & 75\end{array}$

Chapter 7 Research students and the Loughborough Repository conclusions and recommendations 76

$\begin{array}{lll}7.1 & \text { Introduction } & 76\end{array}$

$\begin{array}{lll}7.2 & \text { Limitations of the study } & 76\end{array}$

$\begin{array}{lll}\text { 7.2.1 Research students interviews } & 76\end{array}$

$\begin{array}{lll}7.2 .2 & \text { IR managers survey } & 77\end{array}$

$\begin{array}{lll}7.3 & \text { Recommendations } & 78\end{array}$

$\begin{array}{lll}\text { 7.3.1 Repository content } & 78\end{array}$ 
7.3.2 Organisation of the repository

7.3.3 Intellectual property rights

7.3.4 Providing added value 79

7.3.5 User education and training 80

7.3.6 Promotion \& advocacy 81

7.3.7 Staffing 82

$\begin{array}{lll}\text { 7.3.8 Conclusion } & 82\end{array}$

7.4 Directions for future research 82

$\begin{array}{lll}7.5 & \text { Conclusions } & 84\end{array}$

$\begin{array}{lr}\text { References } & 85\end{array}$

Appendix 1. Emails to prospective respondents 93

A1.1 Email to IR managers 93

A1.2 Email to research students 94

Appendix 2. Research Student Interview Schedule

95 


\section{List of Figures}

Figure 3.1. Information sources used in the literature search. 20

Figure 3.2. Definitions used in the interviews. 25

Figure 3.3. Examples of statements presented to respondents. 26

Figure 5.1. Sources of information used by research students. 42

Figure 5.2. Reason for publishing: to communicate results 44

Figure 5.3. Reason for publishing: to advance career 45

Figure 5.4. Reason for publishing: for personal prestige 45

Figure 5.5. Reason for publishing: to increase chances of gaining funding 46

Figure 5.6. Reason for publishing: for direct financial reward 46

Figure 5.7. Types of work to be deposited in the Loughborough Repository 50

Figure 5.8. File formats to be deposited in the Loughborough Repository 52

Figure 5.9. Types of work students would like to find in the Loughborough

Repository 54

Figure 5.10. Responsibility for tasks involved in depositing work in the Loughborough Repository $\quad 56$

Figure 5.11. Students views on complying with mandatory deposit 58

Figure 5.12. Motivations for depositing in the Loughborough Repository 61

Figure 5.13. Deterrents to depositing in the Loughborough Repository 63 


\section{List of tables}

Table 3.1. IR managers survey: repositories contacted by country.

Table 3.2. Outcomes of the first pilot interview. 27

Table 3.3. Research student responses by faculty and department. 29

Table 4.1 Use of the repository by research students: summary of managers' responses.

Table 4.2 Promoting the repository to research students: summary of managers' responses.

Table 4.3 Is there a place for research student output in the IR? Summary of managers' responses. 


\section{Chapter 1 Institutional repositories and scholarly publishing}

\subsection{Introduction}

This project is undertaken at a time of change. Over the last 15 years, worldwide access to the Internet has irrevocably altered patterns of communication, both formal and informal. One of the major areas of change has been in scholarly communication and, within this, in scholarly publishing. With the advent of freely accessible public, personal, departmental, institutional and subject based web sites and repositories, scholars have more options to disseminate their work than ever before.

This dissertation is concerned with the activities and attitudes of one group of scholars - research students - with respect to this 'open access' publishing. Its focus is the potential role for research students in the new institutional repository (IR) at Loughborough.

This chapter will provide a background to the project by defining some terms and outlining some key issues. The aim and objectives of the project will be stated.

\subsection{Open access - definition}

Open access (OA) is defined as the right to "read, download, copy, distribute, print, search or link to the full text" of articles which are freely available either on the Internet (Budapest Open Access Initiative (Chan et al. 2002)), or in an online repository supported by an academic or similar institution (Bethesda Statement on Open Access Publishing (Suber 2003)). In the OA world, authors' rights extend only to control over the integrity of their work and to being properly acknowledged and cited (Chan et al. 2002).

The two main OA publishing options are therefore submission to an OA journal, or self-archiving in an institutional or subject-based digital repository (Antelman 2004, p.372, Swan and Brown 2004, p.219). Heely and Anderson recommend the following inclusive definition of a digital repository: 
"a managed storage system with content deposited on a personal, departmental, institutional, national, regional, or consortial basis, providing services to designated communities, with content drawn from the range of digital resources that support learning, teaching and research" (Heery and Anderson 2005, p.3).

The institutional type of repository will be the focus of this research.

\subsection{Drivers of open access publishing}

The drivers of OA publishing are technological, financial, ethical and scholarly. They include:

- An increasing audience with widespread access to the Internet.

- Reductions in the cost of online storage.

- Improvements in search and harvesting technology, enabling users to find and access relevant online material efficiently.

- A desire to publish new and supporting material in different formats, for example data sets and multimedia items.

- Increasing concern over the preservation of digital scholarly research material.

- An escalating financial burden on libraries to purchase more journals at prices that are increasing in excess of the rate of inflation (Ayris 2001, p.34, Falk 2004, p.184). This is the 'journal-affordability problem' (Harnad et al. 2005, p.310), or the 'serials crisis' (Banks 2004, p.136).

- Increasing support for the view that the results of research funded by public money are 'public goods' (Berry 2000, p.38) and should be made freely available to the public (i.e. support for the principle of $O A$ )

- Increased pressure on academics to publish, longer lead times in print publishing, and increasing author dissatisfaction with the process.

- Demand for immediate dissemination and research impact.

(Crow 2002, p.5, Lamb 2004, p.146 and Lynch 2003)

The debate over the relative importance of the different issues rages fiercely.

For a flavour of this debate see Harnad's American Scientist Open Access Forum <http://amsci-forum.amsci.org/archives/American-Scientist-OpenAccess-Forum.html>. 
These drivers have motivated authors and users of information to look outside traditional publishing models for complementary ways of sharing research output.

\subsection{Resistance to open access publishing}

Whilst scholars are generally in favour of OA publishing; unsurprisingly, there has been resistance from some commercial publishers. Some of their arguments include:

- OA material is 'free' only at the point of use, there are still costs to be covered - for adminstration, hosting etc. Kaser reports that OA initiatives are simply "new publishers operating on alternate financial models" (Kaser 2003).

- OA publishers provide only the means of distributing work. They do not provide the additional services such as selection, peer review, editing and typesetting which make up a quality product.

- Without peer review, OA publishing is simply 'vanity publishing' which favours those with the ability to pay (Stevenson 2004, pp.83-84, Schroter et al. 2005). It therefore compromises scientific integrity.

- OA threatens the financial position of commercial publishers, particularly the smaller 'learned society' publishers relying on subscription income (Rowland 2005).

These negative perceptions have caused some publishers to be obstructive, even refusing to accept articles that have previously been self-archived in OA repositories (Swan and Brown 2005, p.57) ${ }^{1}$. However, research exists which suggests that OA availability need not be detrimental to traditional publishing. In the area of physics publishing at least, an actively supported subject repository, ArXiv <http://arxiv.org/>, has not adversely affected subscriptions to traditional journals (Morris 2003, p.172, Swan and Brown 2005, p.4). OA proponents insist that OA archiving is complementary to the traditional model (Velterop 2005).

\footnotetext{
${ }^{1}$ Articles deposited prior to publication in a peer reviewed academic journal are known as 'preprints', as distinct from 'postprints' which are posted to repositories after publication.
} 
Morris suggests that more research is needed to provide "solid, factual evidence of the effects of the open access model on all involved in the communication chain" (Morris 2004, p.307).

\subsection{Institutional repositories: definition and description}

An institutional repository is

"an electronic system that captures, preserves, and provides access to the digital work products of a community" (Foster and Gibbons 2005).

Its characteristic features are as follows:

- It is institutionally defined - unlike a subject repository, the IR captures only the intellectual property of the host institution.

- Content may be purely scholarly (Crow 2002), or may comprise administrative, teaching and research materials, both published and unpublished.

- It is cumulative and perpetual - once items are submitted they should not be withdrawn. This carries with it a long term obligation on the host institution to preserve IR content.

- It is open and interoperable - a primary goal of an IR is to disseminate the institution's intellectual product. As a minimum this requires the creation of metadata which can be 'harvested' by appropriate software. In practical terms content should be Open Archives Initiative Protocol for Metadata Harvesting (OAI-PMH) compliant (Rowland et al. 2004, p.299).

- In collecting, storing and disseminating information it contributes to the process of scholarly communication. (from Crow 2002, pp.16-19 and Ware 2004, p.115).

The Joint Information Systems Committee (JISC) have recently been promoting the development of IRs in UK universities through its Focus on Access to Institutional Resources (FAIR) programme (Bruce 2005). Repositories at the universities of Southampton, Glasgow, Leeds, Strathclyde, Nottingham and others have been created as a result of this programme (Pinfield 2003). Their experiences have been well documented in the literature (e.g. Pinfield et al. 2002, Ashworth 2003, Ashworth et al. 2004, Hey 2004, Mackie 2004). 


\subsection{Aims and objectives}

At Loughborough, the library is just starting to develop an IR for the benefit of the whole university, and research is underway to assess the rights and rewards which will be necessary to achieve support for this from university staff ${ }^{2}$. By way of complementing this work, the current project aims to explore and assess the value of the Loughborough Repository (LR) to another potential group of users research students.

\section{Specific objectives are:}

1. To explore previous research into the attitudes and motivations of academic authors, particularly with respect to OA publishing.

2. To establish the potential role of research students regarding the LR both as contributors and as users of information.

3. To compare interdisciplinary differences in research students' attitudes toward the LR.

4. To investigate the role played by research students in more established IRs at other universities.

5. To use the findings of the project to make appropriate recommendations to the managers of the LR.

The remainder of this dissertation comprises a review of the literature concerning authors' use of and attitudes towards IRs (Chapter 2); a description of the research methodology (Chapter 3); an analysis of data collected (Chapters 4 and 5); a discussion of the main findings (Chapter 6); and finally a summary of the conclusions and recommendations arising from the work (Chapter 7). The two appendices contain copies of the research instruments an interview schedule and email survey.

\footnotetext{
${ }^{2}$ Oppenheim, C. et al., 2005. Rights and rewards in blended institutional repositories. Proposal submitted to JISC Digital Repositories Programme, [May 2005].
} 


\section{Chapter 2 Users' attitudes towards IRs: a review of the literature}

\subsection{Introduction}

It is generally agreed that the technical challenges and the costs of installing IR software are relatively minor issues when compared with the time and effort required to persuade users to populate it with their work (Foster and Gibbons 2005, Genoni 2004, p.300, Horwood et al. 2004, p.170). Cultural rather than technological factors limit the use and development of IRs (Hubbard 2003, p.245, Ware 2004, p.116). It is therefore important to understand the attitudes and motivations of the user group if an IR is to fulfil its potential.

This chapter will begin by outlining the potential benefits of IRs to both institutions and individuals, as identified in the literature. Some of the major concerns will then be addressed. After this will follow a description of the outcomes of some recent studies of academic authors' attitudes towards OA publishing and IRs. The chapter will conclude with some suggestions for areas suitable for further investigation.

\subsection{Institutional repositories: benefits to institutions}

\subsubsection{Raising the institutional profile}

"Institutional repositories, by capturing, preserving, and disseminating a university's collective intellectual capital, serve as meaningful indicators of an institutions' academic quality" (Crow 2002, p.6).

In an influential position paper on behalf of SPARC (the Scholarly Publishing and Academic Resources Coalition), Crow firmly places institutional visibility and prestige as a major rationale for IRs. Instead of a diffuse pattern of publication across thousands of scholarly journals, the IR concentrates intellectual product, "making it easier to demonstrate its scientific, social and financial value" (Crow 2002, p.6). If this increased visibility is associated with high quality, the results may be tangible benefits to the institution in the form of continued or new public and private funding, and increased applications from potential students and staff (Prosser 2004). 


\subsubsection{Total intellectual output}

An IR may contain both published and unpublished research material. Much of an institution's unpublished grey literature ${ }^{3}$ is at risk of being permanently lost through lack of organisation and control. The IR provides a structure and service which will allow it to be located, retrieved and preserved indefinitely.

At the other end of the publishing scale, Hall suggests that IRs may become the new university presses. In this scenario, local peer review and quality control will evolve into full scale publishing ventures (Hall 2003, p.33).

\subsubsection{Teaching and learning}

Teaching and learning can be supported by links to IR content from virtual learning environments (VLEs) and the library catalogue (Day 2003). Lecture notes, handouts, presentations and images are all suitable content. Course materials can be shared, 're-purposed' and re-used. Crow (2002, p.23) refers to the benefits of saving "non-ephemeral faculty-produced teaching material".

So far, most repositories for learning objects in the UK have adopted a centralised rather than institutional model. Examples are the JORUM repository <http://www.jorum.ac.uk>, the HLSI service <http://www.hlsi.org.uk> and Curriculum Online <http://ww.curriculumonline.gov.uk>. LORE (Learning Object Repository for Edinburgh) is an example of a localised Higher Education repository service, it is linked to a strategic institutional e-learning programme (Heery and Anderson 2005, p.23). In the US, MIT's OpenCourseWare initiative aims to make MIT course materials available (Mark Ware Consulting 2004, p.20).

\subsubsection{Leverage of existing investment in information systems}

In many institutions the additional infrastructure required to set up an IR is minimal.

Existing computer networks, IT services and library expertise are exploited by the IR, enabling these units to demonstrate even greater efficiency and value for money (Yeates 2003, p.98).

\footnotetext{
${ }^{3}$ For example, working papers, technical reports, conference proceedings, departmental bulletins, grant applications, status reports, committee reports, surveys and technical documentation (Genoni 2004, p.301)
} 


\subsubsection{Supporting institutional record keeping}

An inclusive IR offers practical, administrative benefits. It facilitates records management and reporting (Heery and Anderson 2005, pp.2,4) and supports the institution's obligations regarding health and safety record-keeping, Freedom of Information, and accountability (Heery and Anderson 2005, p.5).

At both Southampton and Glasgow universities, the ability to generate information and documents for exercises such as the University Research Report and the Research Assessment Exercise (RAE) was considered a major benefit (Hey 2004, Mackie 2004). Swan et al. suggest that the potential compilation of an 'institutional CV' is "one of the most persuasive points for an institution considering setting up an archive" (Swan et al. 2005b, p.8).

Harnad et al. advocate that Funding Councils should mandate the maintenance of a standardised online RAE-CV, linked to the full text of every cited refereed research paper in a local IR (Harnad et al. 2003). This, they suggest, will provide a cheaper but richer set of performance data; increase the visibility, uptake and impact of UK research; and provide an example of good practice for the rest of the world to follow.

\subsubsection{Cost savings}

Librarians hope that, in the longer term, widespread adoption of OA publishing will allow savings to be made from institutions' subscriptions to academic journals. However, this is unlikely to occur until a 'critical mass' of content has been achieved (Pinfield 2002, p.262). This outcome, of course, denies the complementarity of OA and traditional publishing models.

\subsection{Institutional repositories: benefits to users}

Benefits to the institution reflect on the individual, but there are further, more direct benefits too.

\subsubsection{Dissemination and impact}

Academic authors produce research papers to share knowledge. They do this for their careers and for personal satisfaction. Success is achieved by disseminating work widely and quickly, with the hope of achieving the maximum impact (Hubbard 2003, p.244, Pinfield 2004). Key features of an IR are its 
openness and interoperability with other services. By making the content of an IR searchable by external discovery tools, an author's work is accessible to other members of the research community. Studies have shown that "the usage of open access research is $330 \%$ greater than for toll-access research" (Lawrence 2001, cited by Harnad [2003?]), and the more an article is downloaded, the more it is eventually cited (Antelman 2004, p.373). Conversely, the more restrictive the access arrangements, the less an article will be read (Kurtz 2004, p.1).

\subsubsection{IR content}

Compared with traditional print publishing, the IR offers the ability to store and provide access to a much wider variety of material. Researchers produce articles and reports, but also "original art, grant proposals, maps, radio/TV interviews, motion pictures, music scores, photographs, consulting (technical) reports, technical drawings, and poster session displays" (Cervone 2004). All of these, once converted to digital format, might be deposited in the IR. Moreover, supplementary material such as supporting evidence and data, interim reports and draft versions of papers, may also be stored.

\subsubsection{Feedback and commentary}

The content of a repository need not have been through a peer review process. In some disciplines it is conventional for researchers to make preprints available to their own research community in order to receive comments or assert priority (Hubbard 2003, p.244). Repositories that serve subjects with these cultures have been found to be particularly successful at attracting content ${ }^{4}$.

\subsubsection{Added value services}

IR systems can produce hit counts on papers, personalised publication lists and citation analyses (Hubbard 2003, p.244, Pinfield 2002, p.262). These tools can create useful post-publication quality indicators (Pinfield 2004). For the individual, monitoring download activity provides a measure of the impact of their research (Swan et al. 2005b, p.8).

In committing to a 'cumulative and perpetual' record of knowledge, the IR also

\footnotetext{
${ }^{4}$ The arXiv repository, which houses material from physics, mathematics, computer science and quantitative biology, has some 300,000 digital items and is accessed about 1.5 million times each month (Swan et al. 2005a, p.26)).
} 
takes responsibility for preserving and maintaining digital items. This offers a considerable advantage over local self-archiving which may be time-consuming and lacking in security (Ware 2004, p.116).

\subsubsection{Networked information}

The IR offers advantages to both 'academics-as-authors' and 'academics-asreaders' (Gadd et al. 2003c, p.171). The same system that facilitates the dissemination of academics' own work also enables them to gain access to the work of others. Internal and external cross-searching is invaluable to multidisciplinary subjects such as the social sciences (Crow 2002, p.10). Repositories that are OAI-PMH compliant are effectively networked together to form a worldwide, openly accessible resource.

Lynch suggests there may be benefits in 'federating' IRs to enable crossrepository search, backup, preservation and disaster recovery capabilities (Lynch 2003). He envisages 'consortial' or 'cluster' IRs in which multiple universities will share the cost and workload of IR maintenance. Crow suggests that multiple mirrored and distributed repositories, varying in location and format, are the best practice model for digital preservation (Crow 2002, p.10). Swan et al. (2005a, p.36) suggest that a 'harvesting' system would be an optimal way of providing access to such a distributed network.

Peters lists other advantages of the consortial approach, namely, increased economies of scale, more comprehensive subject coverage, potential for improved authority control, the avoidance of redundancy (of both expertise and computing capacity) and savings in harvesting effort (Peters 2002, p.416). Examples of consortial repositories are the White Rose Consortium ePrints repository <http://eprints.whiterose.ac.uk/> and the Australian Digital Theses program <http://adt.caul.edu.au/>.

\subsection{Institutional repositories: issues and concerns}

If the benefits of an IR were incontrovertible, then every institution would have one. Perhaps this will happen. However, in the meantime, there are some concerns to address. 


\subsubsection{Cultural change}

The biggest challenge facing IR managers is that of generating content. Some authors suggest that ingrained behaviours, inertia, indifference and resistance to change hamper the adoption of the working practices needed to support the IR (Hubbard 2003, p.246, Ware 2004, p.124). Add to these a lack of awareness about self-archiving and concerns over quality control, copyright, plagiarism and the disruption of the existing scholarly communication system (Pinfield 2004), and it is not surprising that content may be slow in building.

One option is to insist that researchers deposit their work (De Beer 2005, pp. 134-140). However, despite evidence of its acceptibility ${ }^{5}$, most institutions have resisted taking this step. Only the Queensland University of Technology in Australia has so far required authors to self-archive their work if publishers' copyright agreements permit it (Pinfield 2004).

In some universities, students' theses are subject to mandatory deposit. Theses are usually governed by university regulations so the requirement can be relatively easily enforced.

In a very recent development, the Research Councils UK (RCUK) have produced a position statement proposing that from October 2005 output from all funded projects must be deposited in openly available repositories (Research Councils UK 2005). If accepted, this is likely to have a major impact on the quantity of material being deposited in IRs.

\subsubsection{Cost}

Depending on the technological infrastructure and relevant expertise already in place, the initial financial cost of creating an IR may not be high (Steele 2003, p.3). Nottingham University incurred only $£ 3,900$ in set-up costs for their Eprints repository (Swan et al. 2005a, p.33). However, staff costs including time spent drafting policies, arranging licensing agreements, developing guidelines, publicising the repository, training and supporting users and creating metadata, may be significant (Crow 2002, p.28, Horwood et al. 2004, p.174). Ongoing

\footnotetext{
${ }^{5}$ Swan and Brown found that $81 \%$ of authors would willingly deposit an article in a repository if mandated by their employer or sponsor to do so (Swan and Brown 2005, p.63)
} 
costs, such as for hardware and software maintenance or for storage capacity, may be difficult to predict, making financial planning difficult (Baudoin and Branschofsky 2004, p.39) ${ }^{6}$.

\subsubsection{Sustaining support and commitment}

"In order to guarantee success it is vital that repositories meet the short term need of users as well as underpinning the longer term strategic objectives of funders and institutions" (Heery and Anderson 2005, p.15). An IR is a long-term commitment. Maintenance of content, software and accessibility will require funding in perpetuity (Drake 2004). If it is to fulfil expectations, the maintenance of the IR must be an institutional strategic goal. The consequences of failure (whether through lack of funding, policy change, technical difficulties or poor management) may be disastrous. Unlike libraries and other information providers, the IR may hold unique copies of material. Under these circumstances, failure of the IR will mean permanent loss of work and loss of confidence in digital scholarship (Lynch 2003). (Of course, if repository content is mirrored elsewhere, as suggested above (Crow (2002, p.10), Lynch (2003)), this could be avoided).

\subsubsection{Technology}

The implementation and maintenance of an IR require technical support. Some argue that the free open source software upon which most IRs run is too restrictive in its functionality, and its future is too uncertain (Heery and Anderson 2005, p.28). Leung notes that it is important to have an exit or migration strategy (Leung 2005, p.15).

\subsubsection{Preservation}

Digital preservation is dependent on many of the factors mentioned above - it requires sustained commitment, adequate funding and technological support. Despite the methods of long term digital preservation being as yet unproven (Yeates 2003, p.98), responsibility for this must be accepted.

\subsubsection{Power and control}

Lynch is concerned that IRs may be exploited by senior management to exert institutional control or ownership over what has previous been the responsibility

\footnotetext{
${ }^{6}$ Baudoin and Branschofsky (2004, p.39) describe how the DSpace team at MIT were approached regarding the deposit of a single 30-terabyte dataset.
} 
of academics. Lynch believes that it is imperative that management should accept responsibility for the IR without exerting control, and that the IR should not simply become a strategic tool (Lynch 2003). Yeates also notes that the balance of institutional power might be affected as departments adopt IR services at different rates (Yeates 2003, p.98).

\subsubsection{Policy}

The flexibility of an IR creates new challenges for policy makers. For example, as academics move from one institution to another and collaborate with members of other organisations (both public and private), their needs must be accommodated through clear policies on deposit, accessibility and other issues (Drake 2004). Other policies will be necessary on document type and format, preservation, submission and accession procedures, intellectual property rights and metadata quality standards (Pinfield 2003).

\subsubsection{Rights management}

Material placed in an IR will be subject to intellectual property rights. These may be owned by the institution, the author or, in the case of a postprint, a publisher (Gadd et al. 2003a, p.245). Despite the fact that "over $90 \%$ of journals already officially support self-archiving" (Eprints.org 2004), concerns over intellectual property rights are a major deterrent to authors considering posting their work on IRs (Hunt 2001, p.27, Heery and Anderson 2005, p.13) and this has resulted in several repositories being populated with bibliographic records rather than full text. Pinfield et al. (2002) note that it is important that authors are discouraged from signing away their copyright to publishers.

From another point of view, authors may wish to attach conditions to their work. Their sponsors may require confidentiality, their data may have commercial value or their documents may require a restricted circulation. There must be appropriate rights management mechanisms in place to allow or restrict access to content (Crow 2002, p.19). The RoMEO project (Project RoMEO 2003) has extensively considered the rights issues of OA publishing. They recommend the use of Creative Commons licences to express the rights attached to individual research papers (Gadd et al. 2004). 


\subsubsection{Versioning}

One way of avoiding copyright problems is to deposit a unique version of a piece of work, for example a copy produced following feedback from peer review but prior to final publication in a journal. (This is the 'Harnad-Oppenheim' strategy (Pinfield et al. 2002)). Such an article may well be of sufficient quality to serve as a substitute for the formally published item. The difficulty arising from this is that multiple copies will then be in circulation (the 'many-copy problem' (Suber 2004)) and there may be confusion over which should be the 'version of record' (Pinfield 2004). The problem is exacerbated in the case of collaborative authorship when one article may be posted to several repositories.

\subsection{Author attitudes to OA publishing}

The discussion above is based on literature produced by information professionals. In the remainder of this chapter the emphasis is shifted to the attitudes and behaviour of the actual producers and users of OA material. With reference to a series of major surveys, the section will focus on the features that are likely to either motivate or deter authors from contributing to or using an IR.

\subsubsection{Principle of open access}

The principle of open access receives widespread support from authors. From their earliest studies, Swan and Brown found that the majority of authors felt that journals' publishers should make articles available electronically for free (Swan and Brown 2003, p.29). Later, they found that $92 \%$ of OA authors were saying that the 'principle of free access for all readers' was an important reason for publishing in OA journals (Swan and Brown 2004, p.220). Even among authors who published in a traditional journal, Schroter et al. found that "almost all authors supported the concept of open access publishing" (Schroter et al. 2005).

\subsubsection{Awareness}

Levels of awareness of OA issues are variable. Authors may support OA scholarly communication, but lack awareness of specific OA initiatives (De Beer 2005, p.127). Even in their most recent survey, Swan and Brown found that $39 \%$ of researchers were unaware of self-archiving as a means of providing access to their work (Swan and Brown 2005, p.43). 


\subsubsection{Accessibility and impact}

The benefits of accessibility and impact have been shown to be major selling points of the OA model (Section 2.3.1). At one institution, access to the scientific literature and exchange and transfer of information are seen as the main advantages of self-archiving (Hajjem and Harnad 2005).

Authors who have published in an OA journal recognise the following benefits:

- wide and rapid dissemination (Schroter et al. 2005; Swan and Brown 2005, p.10)

- easier and faster literature searching (Schroter et al. 2005)

- more equitable access (Schroter et al. 2005)

- greater and broader readership (Swan and Brown 2004, p.220; Rowlands et al. 2004, p.13)

- more frequent citation (Swan and Brown 2004, p.220; Swan and Brown 2005, p.10)

Unfortunately, the perceptions of authors who have not published in an OA journal are generally more negative. Low readership, impact and prestige were cited as reasons for not publishing in OA journals (Swan and Brown 2004, p.220; Swan and Brown 2005, p.12).

In another survey it was found that authors selected journals on the basis of their access to a highly targeted readership (Rowlands et al. 2004, p.10), they therefore saw no benefit in OA.

It seems that those who are familiar with OA publishing appreciate its merits, but those who are not have concerns which need addressing. This points to a need for user education as part of IR advocacy.

\subsubsection{Author fees}

Some journals' publishers seek to recoup the cost of providing OA to their articles by charging authors fees. Author opinions of this vary. Studies have found that about one half of authors surveyed are willing to pay a small amount (up to $\$ 500$ ) to make their work available to others for free (Cozzarelli et al. 2004, p.1111; Rowlands et al. 2004, p.28). Some say that fees might be 
acceptable if they were paid by grant agencies or institutions (Schroter et al. 2005; Swan and Brown 2004, p.221).

Although author charges are not levied on work deposited in IRs, the issues are relevant because they may impact on the individual's choice of OA publishing outlet.

\subsubsection{Additional services}

Swan and Brown (2003, p.30) asked authors to indicate the relative importance of a number of features offered by electronic journals. The ability to link from citations to cited articles was found to be important to $88 \%$ of respondents. Inclusion of additional data or colour images was important to about half the authors (Swan and Brown 2003, p.30).

\subsubsection{Quality}

The issue of quality is an important one for most researchers. Readers want to find high quality, peer reviewed articles in their field (Swan and Brown 2003, p.31). Harnad sees the peer review function as being independent of the OA function. He recommends that work should be submitted as normal to a refereed journal, then the postprint should be self-archived in a digital repository (Harnad [2003?]). Although alternative quality measures are possible in OA publishing - for example, post publication public commentary and citation analyses - Swan and Brown found that authors were overwhelmingly in favour of traditional peer review for guaranteed quality (Swan and Brown 2003, p.31).

\subsubsection{Rights}

Concern over intellectual property rights falls broadly into three categories:

- Concern that posting to an OA repository will be considered prior publication and may prevent the work from being accepted later for publication in a journal

- Concern that placing an article in a repository will infringe copyright agreements with others, for example employers or publishers

- Concern over control over the work and protection of the author's own rights.

As part of the RoMEO project, Gadd et al. asked authors what their main concerns were about making research papers freely available on the web (Gadd et al. 2003b, p.341). Of the six options offered, the largest group of respondents 
had no concerns, the next largest group was concerned with future publication, and the third largest group worried about breaking agreements with publishers. Authors had fewer concerns over the use and potential abuse of their work (i.e. plagiarism, integrity and commercial use) (Gadd et al. 2003b, p.341).

Exploring author attitudes further, Gadd et al. observed that "most academic authors are primarily interested in preserving their moral rights, and that the protection offered research papers by copyright law is way in excess of that required by most academics" (Gadd et al. 2003b, p.333).

This fairly relaxed attitude toward copyright is replicated in other surveys. Swan and Brown (2005, p.56) noted that authors are not always aware of the full copyright implications of their work; while Rowlands et al. concluded that "authors' views on copyright may be characterised as a mixture of indifference, ignorance ... and principled resentment aimed primarily at commercial publishers ("information should be free")." (Rowlands et al 2004, p.14)

\subsubsection{Practical issues}

Ideally, the practicalities of depositing an item in an IR should not deter authors from doing so. Swan and Brown (2005, p.51) reported that most self-archivers had deposited their articles themselves and found the process became easier with practice (Swan and Brown 2005, p.52). Carr and Harnad (2005) measured the time taken to upload a paper and provide some simple metadata. The average time spent was about ten minutes per paper, but users became quicker as they deposited more items (Carr and Harnad 2005, pp. 5-6). For the few authors finding self-archiving particularly difficult, some form of mediated deposit may be appropriate. This would have the advantage of enabling IR administrators to check and perhaps enhance user created metadata (Pinfield 2001).

\subsubsection{Authors as readers}

Authors as readers appear to be highly satisfied with their levels of access to the journals literature (Rowlands et al. 2004, p.16). Most respondents felt that current access was easier than five years previously. Increased availability of material in IRs is likely to improve access further. 
The RoMEO group focused on the ways in which authors as readers expected to use OA material. They concluded that "academics-as-users do not expect to perform all the activities with open access research papers that academics-asauthors would allow" (Gadd et al. 2003c, p.171).

\subsection{Author attitudes: areas for further investigation}

The purpose of the extensive literature review described above was not only to provide context to the present research project, but also to identify areas worthy of further investigation.

The following points are pertinent:

- There have already been a number of large scale surveys investigating the attitudes of academic authors towards aspects of electronic and OA publishing. These surveys have employed lengthy questionnaires, administered electronically by email or web form.

- As a result of these surveys there exists a large supply of topical questions to draw upon, and detailed results with which to make comparisons.

There are significant omissions:

- There is a dearth of information about the use (as either authors or users) of digital repositories by research students.

- Although several studies have identified the factors which motivate and deter authors from making their work available in an OA format, none have asked respondents to indicate the relative importance of these by ranking them.

- Only a minority of reported studies have used face-to-face interviews.

- The views of those responsible for maintaining IRs have not been systematically surveyed.

The research which is described in the following chapters attempts to fill some of these gaps. 


\section{Chapter 3 Research methodology}

\subsection{Introduction}

This chapter describes the methods used in collecting and analysing data.

Three research techniques were used: a literature review, face to face interviews with research students, and an email survey of people responsible for repositories at other institutions.

\subsection{Literature Review}

Many authors in this field are sympathetic to OA principles and make their work freely available. This meant that literature was relatively easy to find.

\subsubsection{Sources}

The main sources used are shown in Figure 3.1. The list is not exhaustive.

\subsubsection{Search terms}

Searches were performed using both key words and, where possible, subject descriptors from a controlled vocabulary. The following key words and phrases yielded useful results ( indicates truncation):

- Open access / Open archives

- Digital / Institutional repositor*

- Scholarly publications / publishing

- Attitudes / views / opinions

- Authors / academics / scholars / faculty

Terms were combined using boolean operators.

e.g. for a LISA search:

((DE="open access") or (DE="repositories")) and (journals or archiv* or publishing).

Any useful references cited by authors were followed up. 
Figure 3.1. Information sources used in the literature search.

- The Pilkington library (including inter library loan)

- Subscription databases

o Dialog

o Emerald

0 LISA *

o Zetoc*

(*Including alerting services)

- Discussion lists

o American Scientist Open Access Forum

o LIS-SERIALS

- Organisational and institutional web sites

o Dspace.org <http://www.dspace.org>

o e-prints.org <http://www.eprints.org>

o JISC <http://www.jisc.ac.uk>

o SHERPA <http://www.sherpa.ac.uk>

o $\quad$ SPARC < http://www.arl.org/sparc $>$

- OAI service providers

o $\quad$ ARC < http://arc.cs.odu.edu>

o OAlster <http://www.oaister.org/o/oaister/>

- OA journals and databases

o Cogprints <http://cogprints.org>

o DOAJ (Directory of Open Access Journals) $<$ http://www.doaj.org>

o E-LIS (E-prints in Library and Information Science) $<$ http://eprints.rclis.org>

- Bailey's OA bibliography (Bailey 2005)

- Search engines

o Google <http://www.google.com>

o Google Scholar <http://scholar.google.com/>

o Vivisimo <http://vivisimo.com/> 


\subsection{Repository managers' survey}

The purpose of the repository managers' survey was to fulfil an objective of the project, namely:

- to investigate the role played by research students in more established IRs at other universities.

The decision was made to contact those directly responsible for existing repositories and obtain their views.

\subsubsection{Choice of method - the email survey}

Face-to-face interviews were impractical for reasons of both time and cost. Telephone interviews were considered, but rejected in favour of an email survey. The advantages of an email survey were:

- Ease of access. Repositories generally have either a named contact or an email address for feedback.

- Recipients of emails could respond at their leisure, having had time to consider the questions.

- Efficient use of researcher time. The email survey could be undertaken concurrently with the research students' interviews.

\subsubsection{Design of the email survey}

In order to maximise the response rate it was decided that three open ended questions should be asked. These covered student use of the IR, advocacy undertaken, and institutional attitudes toward research student content. They are listed in Appendix 1.1.

\subsubsection{Pilot study}

A list of IRs was taken from the SHERPA website: $<$ http://www.sherpa.ac.uk/contacts>. An email (shown in Appendix 1.1) was sent to the IR project officers for each of the SHERPA development partners (the universities of Nottingham, Edinburgh, Glasgow and Oxford, and the White Rose Partnership comprising York, Leeds and Sheffield universities).

An excellent response rate of $80 \%$ was achieved. One minor change was made to the survey: for repositories containing only electronic theses and dissertations (ETDs) the questions would be rephrased slightly (see Appendix 1.1). 


\subsubsection{Selection of respondents}

URLs for IRs were found on the following websites:

- SHERPA partners: <http://www.sherpa.ac.uk/contacts>, and others: $<$ http://www.sherpa.ac.uk/documents/rep_distrib.html>

- Eprints institution archives registry: <http://archives.eprints.org/index.php?action=browse>

- The Resource Discovery Network: <http://eprints-uk.rdn.ac.uk/stats/?action=table>

UK repositories were the first group to be surveyed. Every listed UK IR was included, a total of 24 institutions. Contact details were obtained from IR websites and emails were composed appropriately for the role of the contact (manager, contact, project officer etc.) and the nature of the repository (institutional, departmental or ETD). Responses were received from 17 institutions, giving a response rate of $71 \%$.

Because of the relative newness of many UK repositories, it was decided that the survey should be extended to more established repositories abroad. Once again, each IR website was visited, but only repositories with significant numbers of records were pursued.

The number of repositories contacted in each country is shown in Table 3.1.

Table 3.1. IR managers survey: repositories contacted by country.

\begin{tabular}{|l|c|c|c|}
\hline \multicolumn{1}{|c|}{ Country } & $\begin{array}{c}\text { Number of } \\
\text { managers } \\
\text { emailed }\end{array}$ & $\begin{array}{c}\text { Number of } \\
\text { managers } \\
\text { responding }\end{array}$ & $\begin{array}{c}\text { Response } \\
\text { rate }\end{array}$ \\
\hline United Kingdom & 24 & 17 & $71 \%$ \\
\hline United States & 24 & 15 & $62 \%$ \\
\hline Australia & 6 & 1 & $17 \%$ \\
\hline Canada & 4 & 1 & $25 \%$ \\
\hline Ireland & 1 & 1 & $100 \%$ \\
\hline Singapore & 1 & 0 & $0 \%$ \\
\hline Total: & $\mathbf{6 0}$ & $\mathbf{3 5}$ & $\mathbf{5 8 \%}$ \\
\hline
\end{tabular}




\subsubsection{Data analysis}

Responses to the three questions were collated into one document. Key themes were identified and the answers were summarized into tables. These were then used as the basis for describing the main research findings (see Chapter 4).

\subsection{Research student interviews}

Two other objectives of this project are

- to establish the potential role of research students with respect to the LR - both as contributors and as users of information, and

- to compare attitudes toward the LR of research students in different disciplines.

It was therefore necessary to canvas the views of research students.

\subsubsection{Choice of method - the face to face interview}

The main options for establishing research students' views were the questionnaire survey and the face-to-face interview. It was decided that the best features of both options should be combined in a face-to-face, structured interview. This offered the following advantages:

- The presence of the interviewer allowed the respondent to seek clarification and offer comment and opinion around the questions.

- The interviewer could ensure that respondents fully understood the terms and concepts referred to.

- The questions were standardised and consistent. Some were open, others closed. The open questions were used to find out background information, while the closed questions elicited the type of answers that could be quantified and compared (Denscombe 2003, p.156).

- The personal interview enabled rich data to be collected relatively quickly.

- Completion rates were likely to be higher than if the questionnaire were administered remotely.

These advantages greatly outweighed the study's disadvantages of being labour intensive and time-consuming. 


\subsubsection{Design of the interview schedule}

A copy of the interview schedule may be found in Appendix 2 .

The objectives of the interview were to:

- Establish the level of knowledge and views of research students concerning open access publishing, digital repositories and, particularly, the LR.

- Achieve this as quickly and efficiently as possible.

- Stimulate students' interest in the LR.

Many of the questions were drawn from the literature review. Some were based on the recent work by Swan and Brown (2005) but most were derived from a combination of studies. The questions were adapted and extended to be relevant to research students.

The interview schedule comprised five parts.

Part 1. The interviewer introduced herself and the project and gathered background information about the research interests and publishing practices of the student. Most questions were open ended, allowing students to choose how much information to divulge. This part promoted conversation between interviewer and respondent and gave the interviewer the opportunity to be friendly and interested.

The final question (Q1.4.1), was a closed question about the student's reasons for publishing work. A five point Likert scale was used (Strongly agree ... Strongly disagree). As with most of the other closed questions in the interview, respondents were shown the questions and possible answers on a card, while the interviewer noted their responses. This practice was well received by students.

Part 2 investigated the students' current understanding of OA publishing. Its purpose was to clarify and reach agreement on the key terms ('open access' and 'digital repository') and establish the respondent's experience of these. Cards displaying definitions of both terms were presented to the students (see Figure 3.2). 
Figure 3.2. Definitions used in the interviews.

Open access is ...

"the right to read, download, copy, distribute, print, search or link to the full text of articles which are freely available either on the Internet or in an online repository supported by an academic or similar institution"

A digital repository is...

"an electronic system that captures, preserves, and provides access to the digital work products of a subject or institutional community"

Part 3 explored some of the practical issues surrounding students' use of the LR. It covered the type of work students would want to either deposit or find in the repository; the file formats they used; and who they felt should take responsibility for different tasks. The part finished with their views on mandatory deposit.

In addition to gathering useful background information, the first three parts of the interview gave students the opportunity to gain greater understanding of the nature of an IR. Questions and comments were encouraged. Given that many of the respondents began with little or no idea about OA publishing or digital repositories, it was essential that the concepts were clearly understood before they started the important fourth part.

Part 4 explored the motivations and deterrents to depositing work in the LR. Initially, an open ended discussion was considered. This would have had the advantages of gathering rich data and perhaps throwing up unexpected results (Gillham 2000, pp. 2 and 10). However, given that prior knowledge of OA publishing was not assumed, students would have had little time to marshal their thoughts. It was therefore felt that a series of closed questions would elicit the most useful data.

Following an initial pilot interview (see below), the format chosen was to present a series of statements on cards (see Figure 3.3) and ask respondents to place each card in an 'agree' or 'disagree' pile. A total of 60 statements were 
presented, 32 cards showed reasons why a student might choose to deposit their work in the LR (i.e. motivations, printed on pale yellow card), 28 cards showed reasons why they might choose not to (i.e. deterrents, printed on pale orange card). To avoid future misconceptions, the interviewer emphasised that not all the statements were necessarily true of the LR.

Figure 3.3. Examples of statements presented to respondents.

I would deposit my work in the Loughborough Repository because...

I support the principle of open access

I would be unhappy about depositing my work in the Loughborough Repository because...

I am afraid it might take too much time

When all cards had been allocated, the cards in the 'agree' pile were sorted into motivations and deterrents. Students were then asked to identify the statements of each type which were most important to them and to place these in ranked order.

Part 5 included only one question: on balance, would the student deposit any of their work in the LR? The respondent was then thanked, and asked if they had any further comments or questions.

\subsubsection{Pilot study}

The interview schedule was piloted in two phases. The first phase concentrated on the length of the interview, the effectiveness of the different types of questions and the ordering of the sections. The outcomes of this pilot interview are shown in Table 3.2. 
Table 3.2. Outcomes of the first pilot interview.

\begin{tabular}{|c|c|}
\hline Issue arising & Change made to interview schedule \\
\hline $\begin{array}{l}\text { Respondent was unclear about the } \\
\text { nature of OA publishing and digital } \\
\text { repositories. }\end{array}$ & $\begin{array}{l}\text { Early on in the interview: } \\
\text { - Establish students' level of } \\
\text { understanding by asking them to } \\
\text { explain what they know of the } \\
\text { different terms. } \\
\text { - Produce cards showing the key } \\
\text { definitions and get acceptance of } \\
\text { these. }\end{array}$ \\
\hline The interview was too long. & $\begin{array}{l}\text { Significantly reduce the detail required } \\
\text { in Part } 1 \text { of the schedule. } \\
\text { Change the format of some questions. }\end{array}$ \\
\hline $\begin{array}{l}\text { Passing the questionnaire backward } \\
\text { and forward between interviewer and } \\
\text { respondent was clumsy and } \\
\text { inefficient. }\end{array}$ & $\begin{array}{l}\text { Print closed questions, and their } \\
\text { answers, on separate cards for the } \\
\text { student to consider while the } \\
\text { interviewer notes the answers. }\end{array}$ \\
\hline $\begin{array}{l}\text { Some rating scales were } \\
\text { inappropriate to the questions. }\end{array}$ & $\begin{array}{l}\text { Simplify the possible responses to } \\
\text { motivating and deterring factors to an } \\
\text { Agree / Disagree dichotomy. Then } \\
\text { establish the relative importance of the } \\
\text { various factors by asking respondents } \\
\text { to rank them. }\end{array}$ \\
\hline $\begin{array}{l}\text { By exploring motivations first, and } \\
\text { deterrents last, the respondent was } \\
\text { left with a very negative view of the } \\
\text { LR. }\end{array}$ & $\begin{array}{l}\text { Randomly present the motivations and } \\
\text { deterrents and stress that not all the } \\
\text { statements are true. }\end{array}$ \\
\hline $\begin{array}{l}\text { Interviewer showed too much } \\
\text { hesitation and uncertainty between } \\
\text { questions. }\end{array}$ & $\begin{array}{l}\text { Prepare introductory sentences for use } \\
\text { between questions. (These to be used } \\
\text { as guidelines and paraphrased, not } \\
\text { quoted exactly). }\end{array}$ \\
\hline
\end{tabular}


The second phase of the pilot study involved testing the new schedule on research students. Eight students were approached by email and four responded. Pilot interviewees were asked to offer feedback on both the questions and the process.

Some of their suggestions included:

- Reassure the respondent at the start that anything they do not understand will be explained.

- Ask if respondents have previously deposited material in a digital repository.

- Encourage the student to explain their responses, especially in Part 4.

- Record each interview so that all comments can be accurately recollected.

They observed that the use of the cards introduced an element of interactivity that was both interesting and enjoyable.

All but the last suggestion were adopted. It was decided not to record the interviews for two reasons. First, despite encouragement, respondents generally offered few comments and those they did make could easily be written down by the interviewer. Second, transcription would have significantly increased the workload and therefore reduced the number of interviews that could have taken place.

After two pilot interviews it was felt that the schedule was satisfactory.

\subsubsection{Selection of participants}

In order to compare the attitudes toward the LR of research students in different disciplines, it was decided that students from one department in each of Loughborough's three faculties should be approached. The intention was to interview similar numbers of students from each of the three faculties. The sample type was therefore a cluster sample of a population comprising all research students in the university. The departments initially chosen were Aeronautical and Automotive Engineering (Faculty of Engineering), Physics (Faculty of Science) and Social Sciences (Faculty of Social Sciences \& Humanities (SSH)).

The reasons for choosing these departments were fourfold:

- they were representative of their faculties 
- as disciplines, they had different publication cultures and therefore potentially different experiences of OA publishing

- they each listed the names of their research students (with email addresses) on their departmental websites

- none was involved in the piloting of the LR itself, nor in other ongoing studies.

Selected research students were emailed individually. To improve the response rate, emails were personalised to the student. An example of an email is shown in Appendix 1.2.

These first emails initiated a trickle of responses, but it was clear that there would be insufficient for the study. Additional departments were then approached, until at least ten students from each faculty were available for interview. The eventual list of disciplines represented is shown in Table 3.3.

Table 3.3. Research student responses by faculty and department. Faculty of Engineering:

\begin{tabular}{|l|c|c|c|c|c|}
\hline \multicolumn{1}{|c|}{ Department } & $\begin{array}{c}\text { No. of } \\
\text { students } \\
\text { emailed }\end{array}$ & $\begin{array}{c}\text { No. of } \\
\text { students } \\
\text { responding }\end{array}$ & $\begin{array}{c}\text { Response } \\
\text { rate }\end{array}$ & $\begin{array}{c}\text { No. of } \\
\text { students } \\
\text { interviewed }\end{array}$ & $\begin{array}{c}\text { Interview } \\
\text { rate }\end{array}$ \\
\hline $\begin{array}{l}\text { Aeronautical and } \\
\text { Automotive } \\
\text { Engineering }\end{array}$ & 49 & 11 & $22 \%$ & 5 & $10 \%$ \\
\hline $\begin{array}{l}\text { Civil and Building } \\
\text { Engineering }\end{array}$ & 44 & 16 & $36 \%$ & 8 & $18 \%$ \\
\hline Faculty total: & $\mathbf{9 3}$ & $\mathbf{2 7}$ & $\mathbf{2 9 \%}$ & $\mathbf{1 3}$ & $\mathbf{1 4 \%}$ \\
\hline
\end{tabular}

Faculty of Science:

\begin{tabular}{|l|c|c|c|c|c|}
\hline \multicolumn{1}{|c|}{ Department } & $\begin{array}{c}\text { No. of } \\
\text { students } \\
\text { emailed }\end{array}$ & $\begin{array}{c}\text { No. of } \\
\text { students } \\
\text { responding }\end{array}$ & $\begin{array}{c}\text { Response } \\
\text { rate }\end{array}$ & $\begin{array}{c}\text { No. of } \\
\text { students } \\
\text { interviewed }\end{array}$ & $\begin{array}{c}\text { Interview } \\
\text { rate }\end{array}$ \\
\hline Human Sciences & 41 & 17 & $41 \%$ & 5 & $12 \%$ \\
\hline $\begin{array}{l}\text { Information } \\
\text { Science* }\end{array}$ & 8 & 4 & $50 \%$ & 4 & $50 \%$ \\
\hline Physics & 19 & 4 & $21 \%$ & 2 & $10 \%$ \\
\hline Faculty total: & $\mathbf{6 8}$ & $\mathbf{2 5}$ & $\mathbf{3 7 \%}$ & $\mathbf{1 1}$ & $\mathbf{1 6 \%}$ \\
\hline
\end{tabular}

* Includes pilot study 
Faculty of Social Sciences \& Humanities:

\begin{tabular}{|c|c|c|c|c|c|}
\hline Department & $\begin{array}{c}\text { No. of } \\
\text { students } \\
\text { emailed }\end{array}$ & $\begin{array}{c}\text { No. of } \\
\text { students } \\
\text { responding }\end{array}$ & $\begin{array}{l}\text { Response } \\
\text { rate }\end{array}$ & $\begin{array}{c}\text { No. of } \\
\text { students } \\
\text { interviewed }\end{array}$ & $\begin{array}{l}\text { Interview } \\
\text { rate }\end{array}$ \\
\hline $\begin{array}{l}\text { Design and } \\
\text { Technology }\end{array}$ & 5 & 4 & $80 \%$ & 2 & $40 \%$ \\
\hline Economics & 1 & 1 & $100 \%$ & 1 & $100 \%$ \\
\hline English & 1 & 1 & $100 \%$ & 1 & $100 \%$ \\
\hline Geography & 20 & 5 & $25 \%$ & 1 & $18 \%$ \\
\hline $\begin{array}{l}\text { Politics, } \\
\text { International } \\
\text { Relations and } \\
\text { European } \\
\text { Studies }\end{array}$ & 17 & 12 & $71 \%$ & 3 & $18 \%$ \\
\hline Social Sciences & 21 & 7 & $33 \%$ & 4 & $19 \%$ \\
\hline Faculty total: & 65 & 30 & $46 \%$ & 12 & $18 \%$ \\
\hline $\begin{array}{l}\text { Total all } \\
\text { faculties: }\end{array}$ & 226 & 82 & $36 \%$ & 36 & $16 \%$ \\
\hline
\end{tabular}

\subsubsection{Data analysis}

Following each interview, the responses were coded into an Excel spreadsheet and comments were collated into a document. When all interviews had been completed, the Excel spreadsheet was imported into SPSS. Frequency tables and descriptive statistics were produced, and some variables were recoded. The output from SPSS was then exported back to Excel to allow charts to be produced.

\subsection{Ethical issues}

Appropriate consideration was given to ethical issues in both exercises.

Because direct contact with human participants was involved, the Loughborough University Ethical Clearance Checklist was completed. The interview group did not include any people in 'vulnerable' categories.

At the start of each interview, students were informed of their rights to withdraw, refuse to answer or withhold their responses from the study. The purpose of the 
interview was reiterated by the interviewer. Participants were assured of the anonymity of their responses. At the end of each interview students were given the opportunity to ask questions and make comments. No concerns were raised.

The emails to IR managers contained sufficient information for respondents to give their informed consent to taking part in the survey, although of course they were under no obligation to do so. The email also gave contact details for the author's supervisor in case of any concerns.

In both exercises every email response received was acknowledged. Particular points raised were addressed in the replies.

When arranging the research student interviews, students' wishes for interview times and places were respected. The interviewer arrived punctually for all meetings. Changes in arrangements for interviews were accommodated wherever possible. If a mutually convenient time could not be agreed then the student was thanked, but their offer declined. Toward the end of the study, when more engineering students were offering to take part than were needed, some offers were politely declined. 


\section{Chapter 4 Institutional repository managers - survey}

\section{results}

\subsection{Introduction}

The purpose of the email survey was to investigate the provision for and role played by research students in other institutional repositories. This chapter presents the results of this survey.

Responses were received from 35 institutions. Thirty-three of these replies included answers to at least one of the questions.

\subsection{Use of the repository by research students}

Repository managers ${ }^{7}$ were asked "What (if any) use do research students make of your repository (either as authors or as readers)?", or (in the case of ETD repositories) "How much use do research students make of your repository (either as authors or as readers)?". Thirty managers responded to this question, their replies are summarised in Table 4.1.

Three overlapping themes recurred in the managers' answers to these questions: the amount of use of the repository by research students, the evidence for this use and the type of material deposited.

\subsubsection{Amount of use}

Fourteen comments were made on the amount of use of the repository by research students. Over half of these replies stated that there was not enough content in the repository or that it was too early to say, for example:

"We have not really enough content on our IR for research students to make use of as yet" (Respondent 1 (UK)).

Even those who stated the level of use often qualified their response:

"As readers, as yet, very little or none. As authors, none. Our repository went live in May and is still very small" (Respondent 2 (UK)).

\footnotetext{
${ }^{7}$ Throughout this chapter the respondents are referred to as 'managers'. This title is for convenience only and does not necessarily represent the actual job title of the person concerned.
} 
Table 4.1 Use of the repository by research students: summary of managers' responses.

\begin{tabular}{|c|c|c|c|}
\hline $\begin{array}{l}\text { Use of repository by research } \\
\text { students }\end{array}$ & $\begin{array}{l}\text { Students } \\
\text { as } \\
\text { authors }\end{array}$ & $\begin{array}{c}\text { Students } \\
\text { as } \\
\text { readers }\end{array}$ & $\begin{array}{l}\text { Students as } \\
\text { either or both } \\
\text { (unspecified) }\end{array}$ \\
\hline \multicolumn{4}{|l|}{ Amount of use: } \\
\hline None & 1 & & \\
\hline Very little use & 2 & 1 & 1 \\
\hline $\begin{array}{l}\text { Not enough content in repository / too } \\
\text { early to say }\end{array}$ & & 3 & 6 \\
\hline \multicolumn{4}{|l|}{ Material deposited: } \\
\hline Bibliographic data & & & 1 \\
\hline Co-authored work (with academic staff) & 3 & & \\
\hline $\begin{array}{l}\text { Grey literature (including talks, papers, } \\
\text { conference publications) }\end{array}$ & 2 & & 1 \\
\hline $\begin{array}{l}\text { Material must be sponsored / approved } \\
\text { by academic staff }\end{array}$ & 2 & & \\
\hline $\begin{array}{l}\text { Peer reviewed, published material only } \\
\text { (or mainly) }\end{array}$ & 3 & & \\
\hline Same as other university members & 1 & & \\
\hline Theses and dissertations & 17 & 1 & \\
\hline Unspecified 'other research work' & 1 & & \\
\hline \multicolumn{4}{|l|}{ Evidence for use: } \\
\hline Anecdotal evidence for use & 3 & 1 & \\
\hline $\begin{array}{l}\text { No data (e.g. download numbers only, } \\
\text { no breakdown by user type) }\end{array}$ & & 13 & 1 \\
\hline No direct response to question & 2 & & 1 \\
\hline
\end{tabular}

(Numbers represent the number of managers giving each response, note that one manager's reply may be represented by several cells).

\subsubsection{Evidence for use}

Although many repository managers collect download counts, and some even make these available online, none of the data collected showed who was doing the downloading, so use specifically by research students could not be established. One respondent said:

"We have download statistics for individual papers, but do not analyse as yet in any great detail where this usage emanates from. A lot of it is from 
within this institution, that much we know, but whether it is specifically research postgrads or staff or even undergraduates downloading the work is unknown at this stage." (Respondent 21 (Australia)).

Indeed, lack of hard data featured in 14 IR managers' replies - one manager even invited the researcher to develop a program to analyse her IR logs, stating "we'd love to have that information" (Respondent 14 (USA)).

Anecdotal evidence for use was offered by several respondents. With respect to students as authors:

"Anecdotal evidence from some of the $200+$ items (mostly theses and dissertations) deposited by PG students suggest that they are keen to disseminate their research to a worldwide audience" (Respondent 6 $(\mathrm{UK})$ ),

while for students as readers:

"informally I know that lots of theses have been seen this way [via Google] from the students telling me (far more than the physical copies are seen that we used to collect)" (Respondent 18 (USA)).

and

"It is clear that the electronic is used far more than the paper or microfiche format" (Respondent 31 (Canada)).

\subsubsection{Type of material deposited}

Twenty-two managers wrote about the type of material being deposited in their IR. Theses and dissertations were by far the most commonly deposited work (with 17 responses). In one institution the deposit of theses is automatic (Respondent 30 (USA)); in another, the institution

"requires graduate students to submit theses and dissertations in electronic format. The ones that are released to the public are hosted in our repository" (Respondent 27(USA)).

Three repositories accept peer reviewed or pre-published material only. A typical response was:

The usual policy for [institution] is to host peer-reviewed articles by staff at the [institution]. However we would certainly consider hosting eprints written by research students as long as they have been peer reviewed" (Respondent 12 (UK)). 
Some repositories have a policy of accepting students' work only if it is coauthored with a member of academic staff, or at least approved by an academic:

"our policy has been that content for DSpace must be faculty sponsored, and preferably faculty authored" (Respondent 14 (USA)).

Others accept a broader range of material, including grey literature:

"research students publish their talks, papers, conference publications..." Respondent 8 (UK)).

\subsubsection{Other comments}

Table 4.1 shows that, with respect to repository use, IR managers have significantly more information about research students as authors than about research students as readers. This is undoubtedly due to the difficulty of collecting detailed information about the IR readership. In an OA environment, IR managers have much more control over who deposits material than who accesses it.

Most repositories have policies regarding who may deposit work, and what type of work they may deposit. In some cases the repositories are too new for these policies to have fully evolved:

"We're still working with senior management at [institution] to firm up what types of material should be deposited in the repository" (Respondent 5 $(\mathrm{UK}))$.

Some institutions have chosen to restrict content in some way (as described above), but others have seen a greater potential, both in terms of providing new services:

"our primary motive for having an institutional repository is to serve the research needs of our faculty and students. We are particularly concerned with grey and born digital literature; ensuring preservation and access for future research needs" (Respondent 28 (USA))

and as an educational tool:

"the archive serves a number of other purposes which are relevant to research students: it shows the range of research activities undertaken at [institution] and it encourages both students and staff to be aware of the processes behind academic publishing and scholarly communication, it also brings the issue of copyright to the fore" (Respondent 11 (UK)). 


\subsection{Promoting the repository to research students}

The second question in each email addressed the issue of advocacy. Managers were asked "Have you promoted the repository specifically to research students?" or (for ETD repositories) "How have you promoted the repository to research students?". Their answers are summarised in Table 4.2. Again, three themes were identified.

Table 4.2 Promoting the repository to research students: summary of managers' responses.

\begin{tabular}{|c|c|c|c|}
\hline & $\begin{array}{l}\text { Students } \\
\text { as } \\
\text { authors }\end{array}$ & $\begin{array}{l}\text { Students } \\
\text { as } \\
\text { readers }\end{array}$ & $\begin{array}{l}\text { Students as } \\
\text { either or both } \\
\text { (unspecified) }\end{array}$ \\
\hline \multicolumn{4}{|l|}{ Promoted or not? } \\
\hline Yes (no further details given) & 1 & & 2 \\
\hline No (no further details given) & 2 & 2 & 6 \\
\hline Not enough content to promote & & 1 & 1 \\
\hline Not yet, but intend to & 1 & 1 & 2 \\
\hline $\begin{array}{l}\text { Not yet, but might when there is } \\
\text { a critical mass of papers }\end{array}$ & & 1 & \\
\hline \multicolumn{4}{|l|}{ Promoted to whom? } \\
\hline $\begin{array}{l}\text { Promoted to academic staff } \\
\text { only }\end{array}$ & & 1 & \\
\hline $\begin{array}{l}\text { Promoted to academic staff and } \\
\text { research students (no } \\
\text { distinction) }\end{array}$ & 1 & & 2 \\
\hline $\begin{array}{l}\text { Promoted to research students } \\
\text { specifically (e.g. via research } \\
\text { training sessions) }\end{array}$ & 4 & 3 & 2 \\
\hline \multicolumn{4}{|l|}{ Means of promotion } \\
\hline $\begin{array}{l}\text { Links to electronic theses } \\
\text { included in library catalogue }\end{array}$ & & & 1 \\
\hline Via library web site & & 2 & 1 \\
\hline $\begin{array}{l}\text { Training sessions / seminars / } \\
\text { workshops }\end{array}$ & 2 & 4 & 2 \\
\hline Presentations & & & 1 \\
\hline Leaflets, posters, newsletters & & 1 & 1 \\
\hline No direct response to question & & & 4 \\
\hline
\end{tabular}

(Numbers represent the number of managers giving each response, note that one manager's reply may be represented by several cells). 


\subsubsection{Is the repository promoted?}

Three managers commented that their IR had insufficient content to justify promoting it to research students, but four said that although they hadn't so far promoted it, they might consider doing so in the future:

"We are planning on an advertising push in the fall when students return. We've spent the spring and summer building content." (Respondent 28 (USA)).

A large number (nine institutions) had not promoted their repository to research students at all. One manager believed that there was no need for promotion:

"If we have quality materials, we believe that students will find it and use it" (Respondent 23 (USA)).

Another felt that:

"the repository is currently accepting peer reviewed articles only so it is more relevant for post PhD researchers" (Respondent 12 (UK)).

\subsubsection{To whom is the repository promoted?}

Of those who had promoted their IR, the majority (eight of the eleven who commented) said they had promoted it to research students specifically; three had promoted it to both staff and students, and one had targeted only academic staff:

"our priority has been to build up the repository and encourage academics to submit their papers for inclusion ... We have held 2 advocacy events in [institution] which were aimed at academics" (Respondent 10 (UK)).

\subsubsection{Means of promotion}

The ways in which IRs are promoted are many and varied. One manager commented:

"we have specifically worked with School Directors of PG studies to discuss strategies to voluntarily collect material from research students (specifically theses). Strategies have included offering free binding of theses, to general awareness/promotion work" (Respondent 6 (UK)) . Another wrote:

"we speak about it to research students at seminars on preparing for higher degrees and at thesis writing seminars, we talk to groups of research students within individual schools, we talk about the ePrints 
service in training classes for postgraduate students. There are also leaflets and posters in schools, and we regularly promote the service to staff and students through [institution] news outlets" (Respondent 21 (Australia)).

The IR is frequently introduced to research students during routine research training sessions. Managers have used these to promote the benefits of depositing:

"I used the session to highlight the issue of copyright (and signing it away) and to encourage the newer researchers to deposit their work. One particular selling point is the potential impact of open access deposit on subsequent citation rate (of interest to all academics not just new researchers / research students)" (Respondent 5 (UK)).

In other training sessions the IR is simply promoted as another resource.

The 'IR as resource' theme is echoed in other forms of promotion. For example, several institutions have placed links to their repository on their library website or catalogue (Respondent s14 (USA) and 25 (USA)).

\subsubsection{Other comments}

Promotion is undertaken with enthusiasm by individuals in some institutions:

"the head of one of our champion departments has said that he will make deposit mandatory for his doctoral and post-doc students, on pain of losing their travel grants!" (Respondent 2 (UK)),

but as far as research students are concerned, others have yet to get started:

"this is something we definitely intend to start doing" (Respondent 9 (UK)); and

"We publicise [the eTheses repository] at postgraduate seminars on publishing. This publicity is fairly recent and we are considering other ways to promote and encourage its use" (Respondent 24 (UK)).

\subsection{The repository as a place for research student output}

The final question gave repository managers the opportunity to air their views about the principle of research students using their IR. They were asked: "Do you think there is a place for research student output in your repository?" or, for ETD repositories, "Is your repository only for theses or do you think there is a 
place for other research student output in your repository?". The responses are shown in Table 4.3.

Table 4.3 Is there a place for research student output in the IR? Summary of managers' responses.

\begin{tabular}{|l|c|}
\hline \multicolumn{1}{|c|}{ Response } & Number of replies \\
\hline No & 0 \\
\hline Deposit with no conditions & 9 \\
\hline Yes (no further details given) & 2 \\
\hline Yes, eventually & 5 \\
\hline Yes, for research student publications of any type & 1 \\
\hline $\begin{array}{l}\text { Yes, research students have the same needs as } \\
\text { other researchers and academic staff }\end{array}$ & \\
\hline Deposit under specified conditions & 4 \\
\hline Yes, for peer reviewed work & 5 \\
\hline Yes, for theses \& dissertations & 1 \\
\hline $\begin{array}{l}\text { Yes, if recommended by a member of academic } \\
\text { staff or department }\end{array}$ & 4 \\
\hline Yes, in a separate repository & \\
\hline No response & 1 \\
\hline No official policy & 4 \\
\hline No direct response to question & \\
\hline
\end{tabular}

It is immediately apparent from Table 4.3 that repository managers overwhelmingly believe that there is a place for research student output in their repositories, but in some cases only under certain circumstances.

\subsubsection{Deposit without conditions}

Of the 17 respondents who felt that there was a place for research student output in their repositories, some were unequivocal:

"Yes, definitely" (Respondent 17 (USA))

"Absolutely" (Respondent 20 (USA)).

One respondent considered that the IR needs of postgraduate students were no different from those of other researchers:

"I do think the IR will be a boon to research students - they publish papers 
and have research output as do post-doc researchers and academic staff. In any case, they're often writing jointly with their supervisors. And they often need to access research by others" (Respondent 4 (UK)).

In another example, repository policy allows previous as well as existing students to deposit work:

"Yes, postgraduate students are encouraged to participate ... and they can continue to contribute work to the repository even after they graduate. We have one ex student who intends to use [repository name] as his research repository throughout his career ... The service is open to all [institution] staff and postgraduate students, both past and present (and future, of course)" (Respondent 21 (Australia)).

\subsubsection{Deposit with conditions}

Although being positive in principle about accepting research student output, five managers qualified their response by stating it must be of a certain type (e.g. a thesis or dissertation), while a further four said it must have been through some form of quality control (e.g. peer review):

"Yes, if it meets the criteria we have set for the [repository] service, i.e. material must be published in either a peer-reviewed journal or be a published conference paper, book chapter or monograph. We have also established a separate repository using the DSpace software ... which contains material such as grey literature, pre-prints and theses, and we would be happy for appropriate material produced by research students to be deposited here" (Respondent 9 (UK)).

One put the responsibility for quality control onto individual members of academic staff:

"students' work must be recommended by a member of academic staff and the staff themselves will upload the paper(s) onto the repository" (Respondent 10 (UK)),

while another stated:

"We haven't got to grips with the quality issue yet but see this as being an issue for our academic schools to regulate" (Respondent 11 (UK)). 
place the work in a separate repository (four responses):

" as the ideas of institutional repositories becomes more commonplace I think exploring the addition of student produced research makes sense, though kept in its own collections or in another instance of our current IR software." (Respondent 30 (USA)).

\subsubsection{Other comments}

Repository managers offered some interesting ideas about the role of research students and their work. One manager commented:

"in the absence of a national solution for making $\mathrm{PhD}$ theses available online ... I could see the development of a separate repository (either at the institutional level or, possibly, across [a consortium]) for the deposition of theses" (Respondent 5 (UK)).

Several felt that encouraging research students to deposit their work was important in setting a habit for later on:

"It is also important to start encouraging researchers to use and deposit in repositories at an early stage in their academic careers" (Respondent 9 $(\mathrm{UK}))$.

\subsection{Conclusion}

This chapter has described the views of IR managers as expressed in their responses to the email survey. The views are those of individuals, but these people represent a cross-section of repositories of different sizes, ages and geographical locations.

In the next chapter the students' views of the IR will be established. The two chapters together will then form the basis of the discussion and recommendations for the $L R$. 


\section{Chapter 5 Research student interviews - results}

\subsection{Introduction}

This chapter describes the main findings of the 34 interviews with research students.

\subsection{Information seeking and publishing}

\subsubsection{Sources of information}

Students were asked how they went about finding material for their research, and in particular, which sources they used. The results are shown in Figure 5.1.

Figure 5.1. Sources of information used by research students.

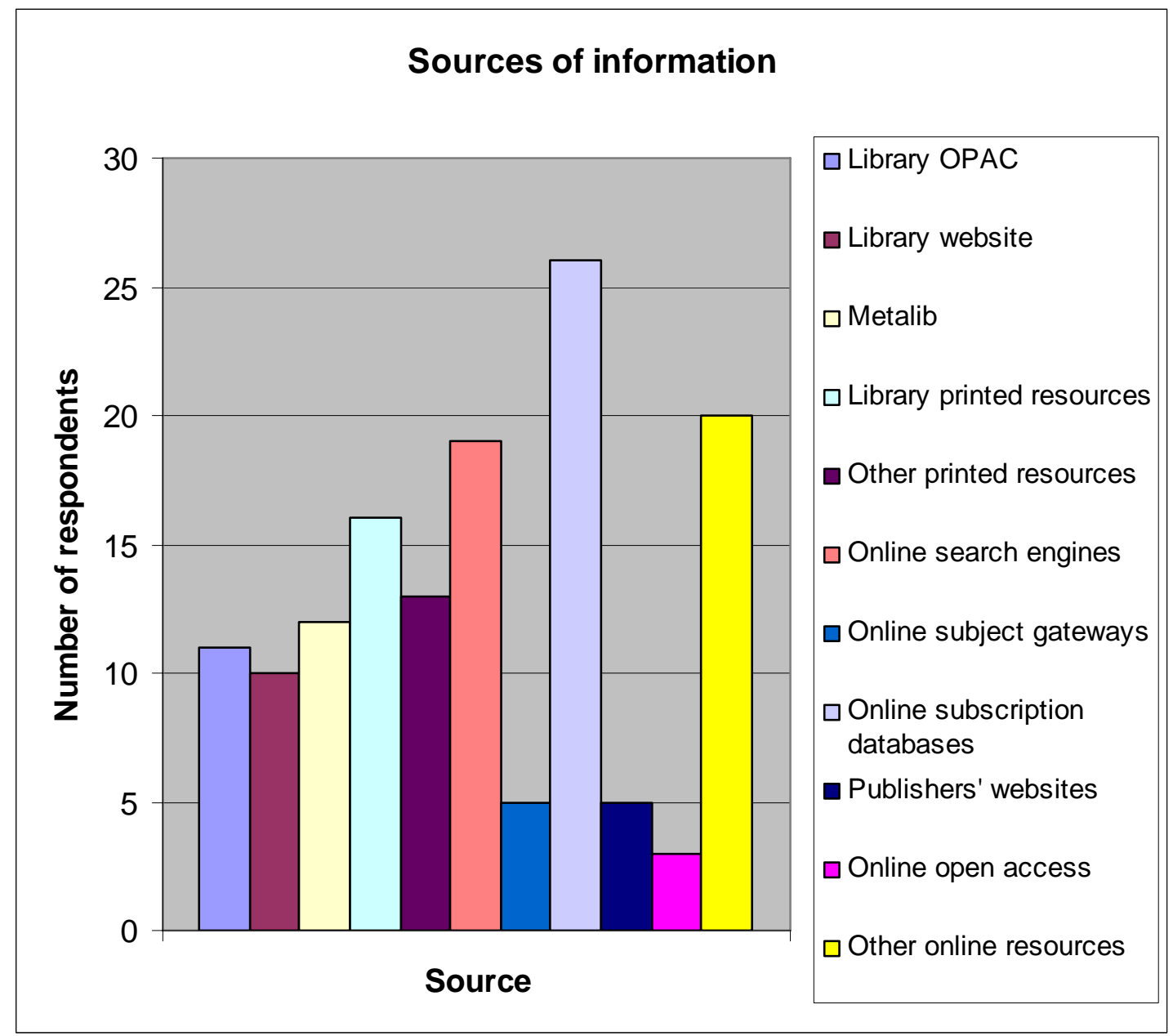


The most popular source was the online subscription database, this was mentioned by 26 students. Nine of these specified 'Web of Science', others mentioned Zetoc (5 students), Ingenta (3), Science Direct (3), CSA (1), Dialog (1), Emerald (1) and PsycINFO (1). Three students had signed up to the Zetoc alerting service to ensure they were informed of the latest developments in their subject area.

The second most popular source was the online search engine. Google and Google Scholar were clear favourites. For some students these were the preferred starting point for a literature search.

Research students were quite active in sourcing information from less accessible places. They used other academic libraries, both officially via the SCONUL scheme, and unofficially through friends; they visited medical and organisational libraries; they contacted authors directly and received papers via email; they borrowed papers and dissertations from their supervisors and departments; and they acquired conference proceedings and trade publications. They exchanged Athens passwords with students at other universities to enable them to access additional electronic resources. Although enterprising, this violates the terms of their agreement with Athens and is not condoned here.

OA sources were the least accessed of all. Only three students mentioned these.

\subsubsection{Publishing history}

Of the 34 research students interviewed, 28 had previously made their work publicly available. Sixteen had published articles, mostly in publications that were available in both printed and electronic form; 14 had produced conference papers and 14 specified other publications, for example their own or departmental websites.

As for why they made their work available where they did, the reasons given were as follows:

- Influenced by supervisors or colleagues

- Influenced by research funders

- Influenced by co-author

- Recognised / reputable / authoritative publication for the subject area 
- To get feedback (e.g. via own website or after emailing a paper to another researcher)

- To meet and exchange ideas with others in the field (e.g. when delivering a conference paper)

- Convenience / local contact (e.g. journal editor is in same department)

\subsubsection{Reasons for publishing}

All 34 students agreed that it was important to publish, but their reasons for publishing varied. The answers are shown in Figures 5.2 to 5.6. Although the faculty breakdown is shown for each of the responses, there is no significant difference between the categories ${ }^{8}$.

Figure 5.2. Reason for publishing: to communicate results

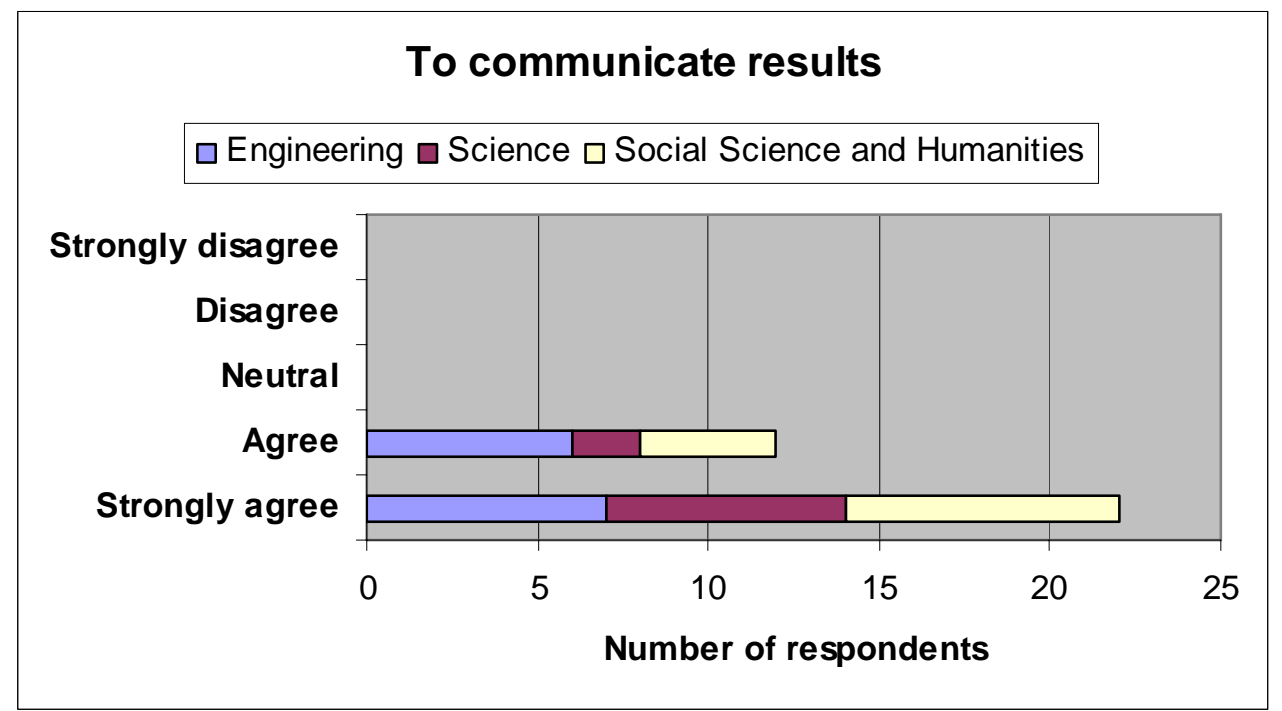

Figure 5.2 shows that all the students agreed that it was important to publish in order to disseminate research findings. Students from the Faculty of Science felt particularly strongly about this.

\footnotetext{
${ }^{8} \mathrm{~A}$ chi-square test was performed on these data, and on a number of other variables, but the outcome was not significant and the low number of participants rendered the results invalid.
} 
Figure 5.3. Reason for publishing: to advance career

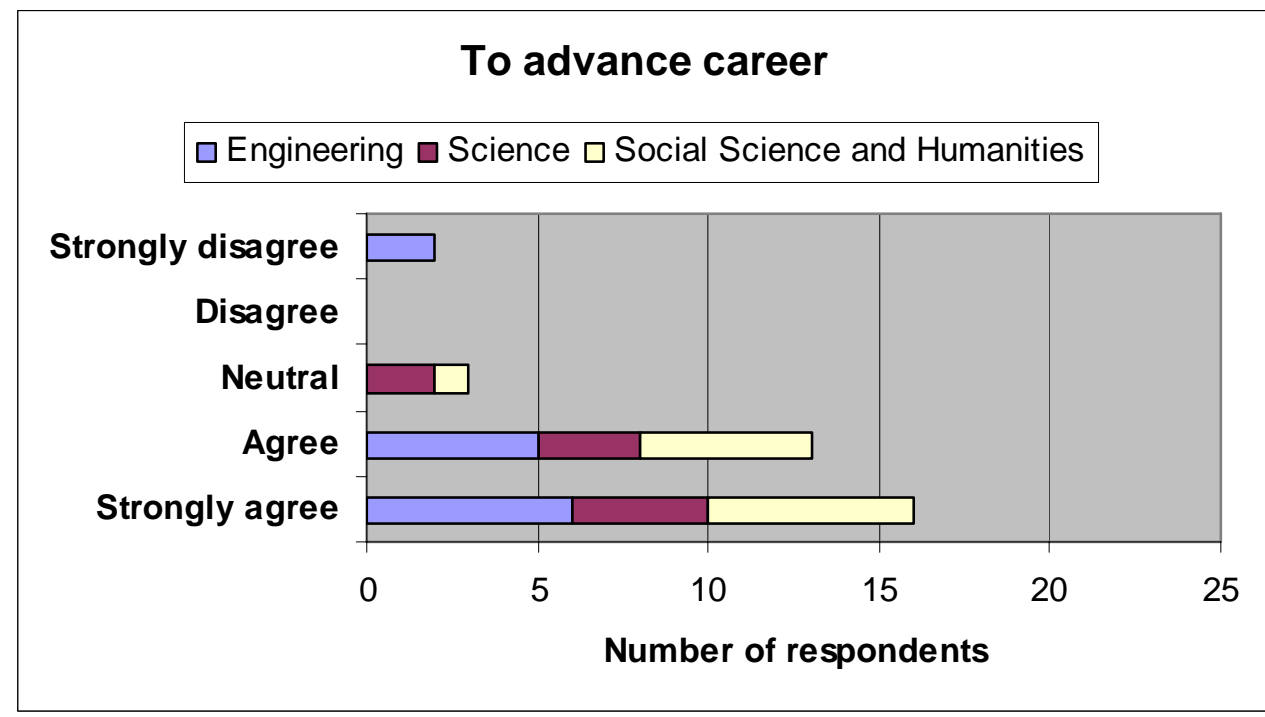

Most students agreed that publishing was important for advancing their careers. Those that disagreed generally commented that they were not planning an academic career, therefore publishing was not relevant to them.

Figure 5.4. Reason for publishing: for personal prestige

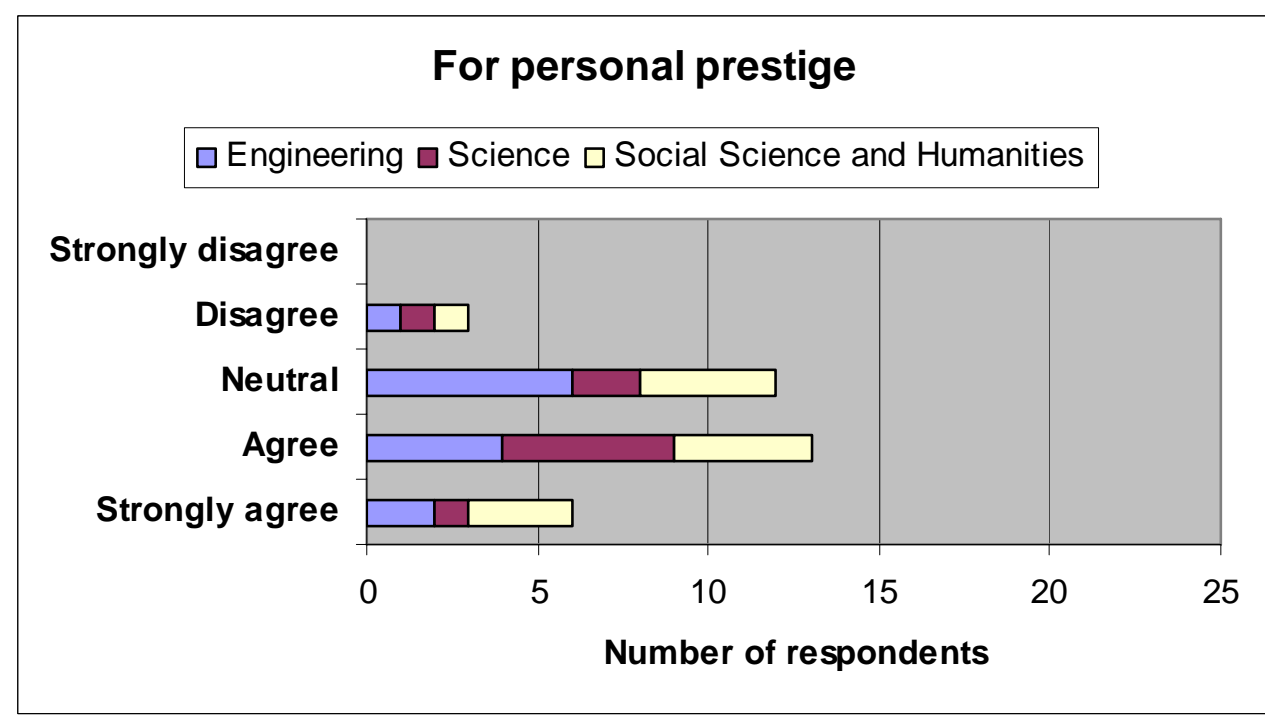

Responses to the question of personal prestige were more varied, with just over half $(55.8 \%)$ of the students agreeing that publishing was important for personal prestige, and the remainder being either neutral (35.3\%) or disagreeing (8.8\%). Individual comments varied from "everyone wants to be good in his field" (Research student 18 (Engineering)), to “it doesn't just go on publications" (Research student 23 (Science)). Again, some students' replies were influenced by their future plans for an academic career. 
Figure 5.5. Reason for publishing: to increase chances of gaining funding

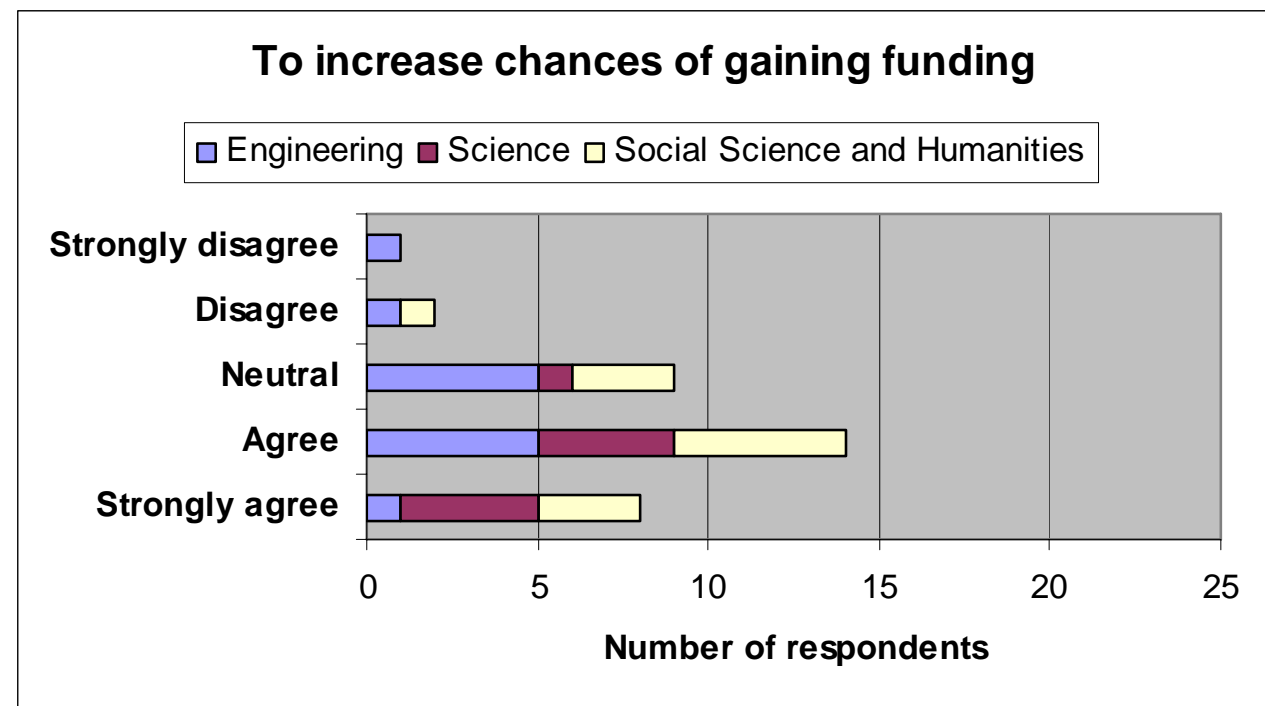

The pattern of responses in this question was similar to that for personal prestige although slightly more (64.7\%) were in agreement with the statement.

Figure 5.6. Reason for publishing: for direct financial reward

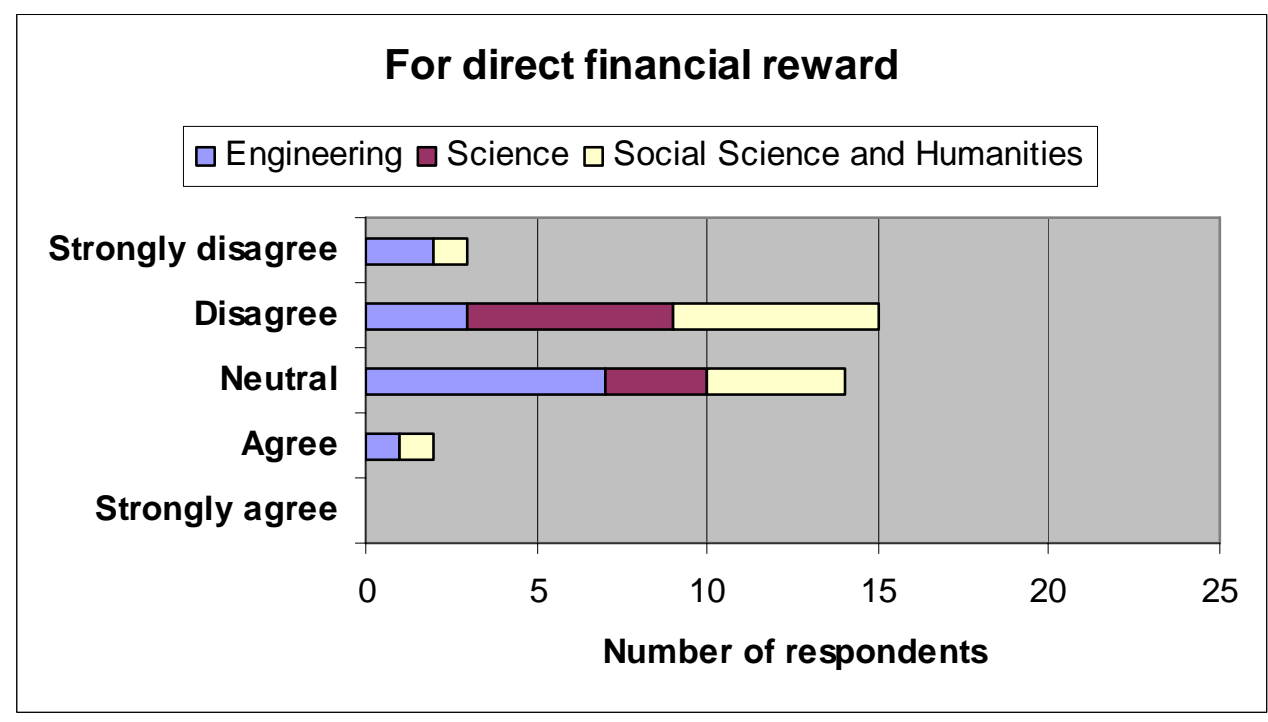

This question elicited by far the most negative responses. Students had generally not received any financial reward for their publcations and did not feel it was a motivating factor.

Having responded to these closed questions, students were asked whether they could suggest any other reasons for publishing their work. Twenty-two students gave additional reasons. These included:

- To get feedback

- To vindicate the quality of their PhD work 
- To communicate to practitioners in the field (as distinct from other academics)

- Because it was expected

- To make others aware of the work, especially those that might benefit from it (e.g. certain social groups or lobbyists)

- For the benefit of the research group (rather than the individual)

- To show what the student's time has been spent on, and to provide evidence for appraisals

- To prove oneself

- To develop arguments which will help the thesis and viva

- For personal satisfaction (including seeing one's name in print)

- For peer acceptance

\subsection{Open access publishing}

\subsubsection{The OA movement}

Although just over half (55.9\%) of the students said they knew what was meant by 'open access', their understanding varied considerably. Responses ranged from

"Making information freely available to everyone, especially scientific and academic or scholarly information" (Research student 3 (Science))

and

"Where people can put their results or peer reviewed work on the web, and others can access and download them without paying a subscription" (Research student 34 (SSH))

to

"Free on the web" (Research student 7 (Engineering))

or

"Shareware" (Research student 32 (SSH)).

Most had grasped the idea that OA work was available to everyone, and most understood that it was free of cost to the user. One or two went on to elaborate, mentioning issues such as removing restrictions on access to databases (particularly in developing countries); standardisation and the compatibility of metadata; and the freedom from passwords or membership. 
Of the few who were aware of the OA 'movement', even fewer could say how they knew about it. One had read about it in a trade paper (Information World Review), another had heard about it on a Radio 4 programme. A couple had come across OA papers whilst searching for information for their projects. The categories derived from Swan and Brown's survey (Swan and Brown 2005, p.48) proved to be inappropriate for this sample of research students.

\subsubsection{The serials crisis}

Eight research students said they had heard of the 'crisis' in scholarly publishing. They talked about the increasing pressure to publish and the move towards digital information. When asked for their views, some of the issues raised included:

- The need for publishers to make revenue, but also the need for freely available scholarly information to help further development (Research student 3 (Science))

- Increasing electronic subscription rates

- Library budgets increasing less than journal costs

- The advantage to a disabled person of being able to access more material on the web (Research student 7 (Engineering))

- The time it takes to publish work

- The relative prestige of new journals compared with existing ones, and the possible devaluation of the quality of research output (Research student 34 $(\mathrm{SSH}))$

\subsubsection{Digital repositories}

Slightly under half $(41.2 \%)$ of the interviewees claimed to know what was meant by a 'digital repository', although more than this were able to make a good guess. Some of their descriptions were very simple:

"Store of work" (Research student 4 (Engineering))

"Big computer database" (Research student 30 (Science))

"Reservoir of information" (Research student 19 (Engineering))

One had ambitious views:

"Digital version of the British Library" (Research student 3 (Science))

Other students gave more information:

"Any information, document, in a digital format, on a server, accessed by 
others. Including best practices, templates for documents, and code. It version controls the document" (Research student 5 (Engineering))

or

"Virtual domain where research papers can be collected and stored where anybody can access and use them" (Research student 29 (SSH)).

Only seven students were aware that they could deposit their work in a digital repository, and only one had actually done so.

Having accepted the proffered definition of a digital repository (see Figure 3.2), seven students said they were aware of subject repositories in their field, and another seven knew of an IR. Subject repositories mentioned included CFD Online, the GNU Scientific Library, the Environment Agency website, the World Bank, Psypag (Psychology Postgraduate Affairs) and the Home Office. To include some of these as 'subject repositories' requires a fairly loose interpretation of the definition.

IRs mentioned included Cambridge University, the University of Washington Department of Mathematics and the Queen's Medical Centre.

\subsubsection{The Loughborough repository}

Unsurprisingly, none of the research students had been aware of the proposed LR before being contacted regarding this project.

\subsection{The Loughborough repository: practicalities}

\subsubsection{Type of work to be deposited}

The students were asked to say which of a list of 15 types of work they would want to deposit, assuming that they were both willing and able to do so. Possible responses for each were 'Yes', 'No' and 'Don't know'. The results are shown in Figure 5.7. 
Figure 5.7. Types of work to be deposited in the Loughborough Repository
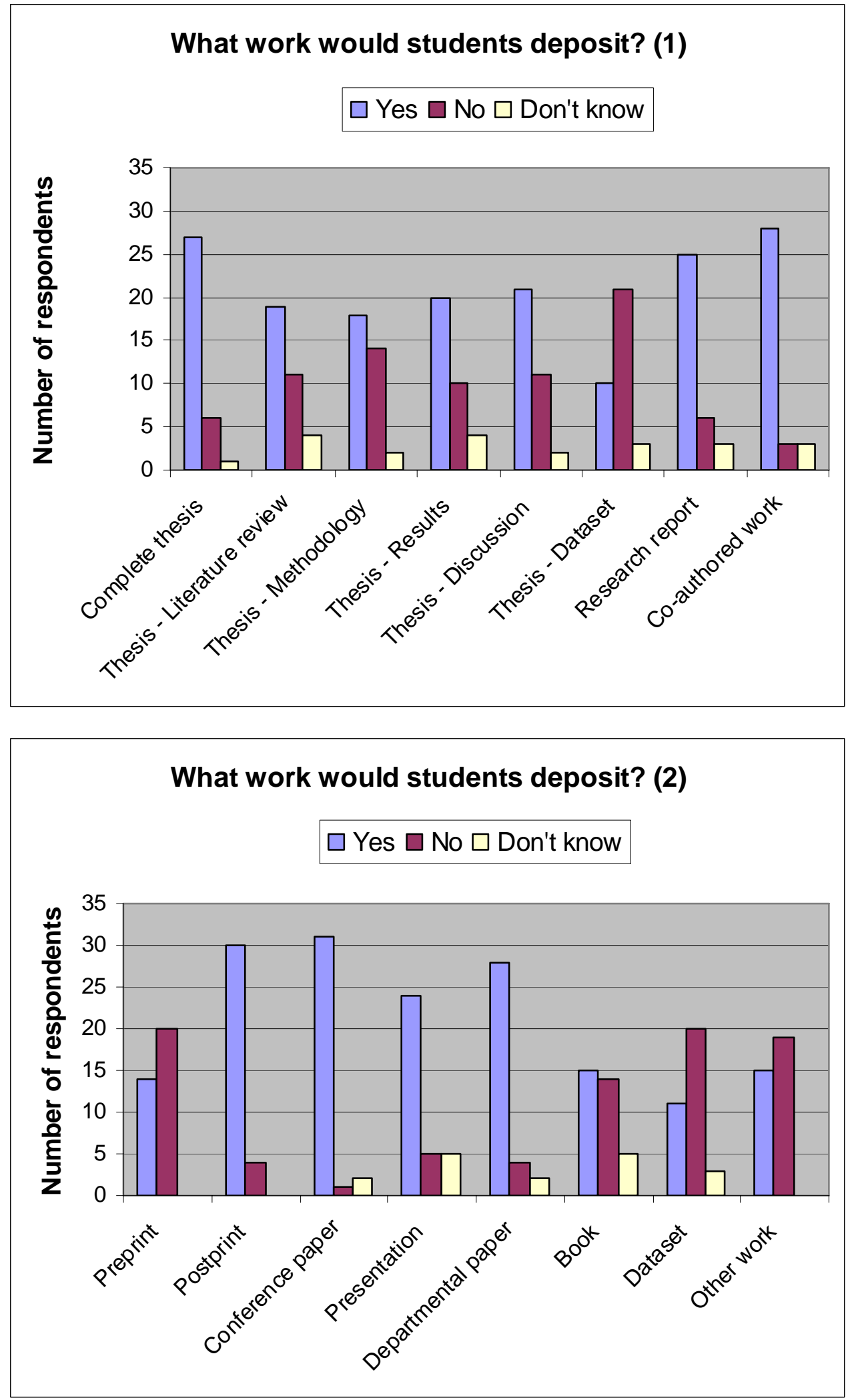
Students showed the greatest agreement in depositing conference papers (31 students or $91.2 \%$ said 'Yes'). Postprints (30, 88.2\%), departmental papers (28, $82.4 \%)$, co-authored work (28, $82.4 \%$, assuming the co-author agreed), and the complete thesis $(27,79.4 \%)$ all had more than $75 \%$ of students saying 'Yes'. A small number of students were adamantly against depositing their thesis, largely because they feared that others would take their ideas. One said the thesis would normally be the basis of a first book.

Research students were most negative about depositing datasets (21 students or $61.8 \%$ said 'No' to depositing the dataset from their thesis, and 20 students, or $58.8 \%$ said 'No' to depositing datasets generally). Reasons for this included concern over confidentiality, ethical issues, students' use of research group rather than individually collected data, the expense of collecting data, and students' desire to use their data themselves further.

Students were also concerned about depositing preprints (20 or $58.8 \%$ said 'No') and books (14, 41.2\%). A significant number chose not to deposit the individual parts of their thesis separately, one reason given was concern over the need for subsequent changes to the work, another student cited potential problems over cross-referencing between different parts of the thesis.

Several students were concerned about the quality or usefulness of their work, saying they would only deposit

"anything of interest to anyone else" (Research student 6 (Engineering)). and that

"Work must be helpful and meaningful to others" (Research student 10 (Engineering))

Some students expressed concern over copyright issues (especially with regard to postprints and books); others were happy to deposit what they considered to be 'formal' pieces of work (e.g. conference papers and postprints) but not the 'informal' items (such as departmental papers and presentations).

When asked to specify any other material that they might want to deposit, just under half (15 or $44.1 \%)$ of the students made suggestions. These included software code (suggested by several Engineering students); collections of references and bibliographies; audio presentations for visually impaired people; 
executive summaries; images and artwork; 'unused' thesis chapters (i.e. written up material that is left out of the final thesis but still makes a worthy contribution in its own right); and administrative documents such as applications for funding and research proposals.

\subsubsection{File formats}

In this question, research students were asked which file formats they generally used and therefore might wish to deposit. Fourteen file types were offered, as was the chance to specify any other file type. The students' responses are displayed in Figure 5.8.

Figure 5.8. File formats to be deposited in the Loughborough Repository



There are clear differences between the file formats. PDFs and word processed documents are the most commonly used, with 31 (91.2\%) and 26 (76.5\%) students respectively. Other popular formats are presentations $(22,64,7 \%)$, HTML $(21,61.8 \%)$ and images $(20,58.8 \%)$. 
Several formats were chosen by very few students, these were desktop publishing files, XML, ASCII, rich text format databases, and technical drawings and sound files.

The phrasing of this question caused some difficulty. The confusion arose because of the two part nature of the question. Some students simply assumed that any file format they created whould be deposited. Others, perhaps those who were more technically aware, recognised that not all formats offered the same facilities when archiving. Thus, a typical response for the latter group was to say 'Yes' to any file format that wasn't amendable, but 'No' to any that was. This stemmed from students' fear of other people altering or plagiarising their work. One interviewee stated that they would use Microsoft Word as a working tool, but would not wish to deposit this format

"because it can be copied and pasted" (Research student 25 (Engineering)).

Most students believed that an appropriately formatted PDF file was the most suitable format, describing this as "more user friendly" and "visually much easier" (Research student 31 (SSH)).

Once again, the 'other' file formats suggested by students included program code.

\subsubsection{The research student as reader}

Research students as readers were in many cases keen to find materials they wouldn't themselves have deposited. Statements such as

"I would like to see as many materials as possible" (Research student 22 $(\mathrm{SSH}))$,

or

"anything I can get my hands on" (Research student 7 (Engineering)) combined with a full set of 'Yes' answers, were typical.

The overall results are shown in Figure 5.9. The charts show that many more students have said 'Yes' to each of the types of work. 
Figure 5.9. Types of work students would like to find in the Loughborough Repository
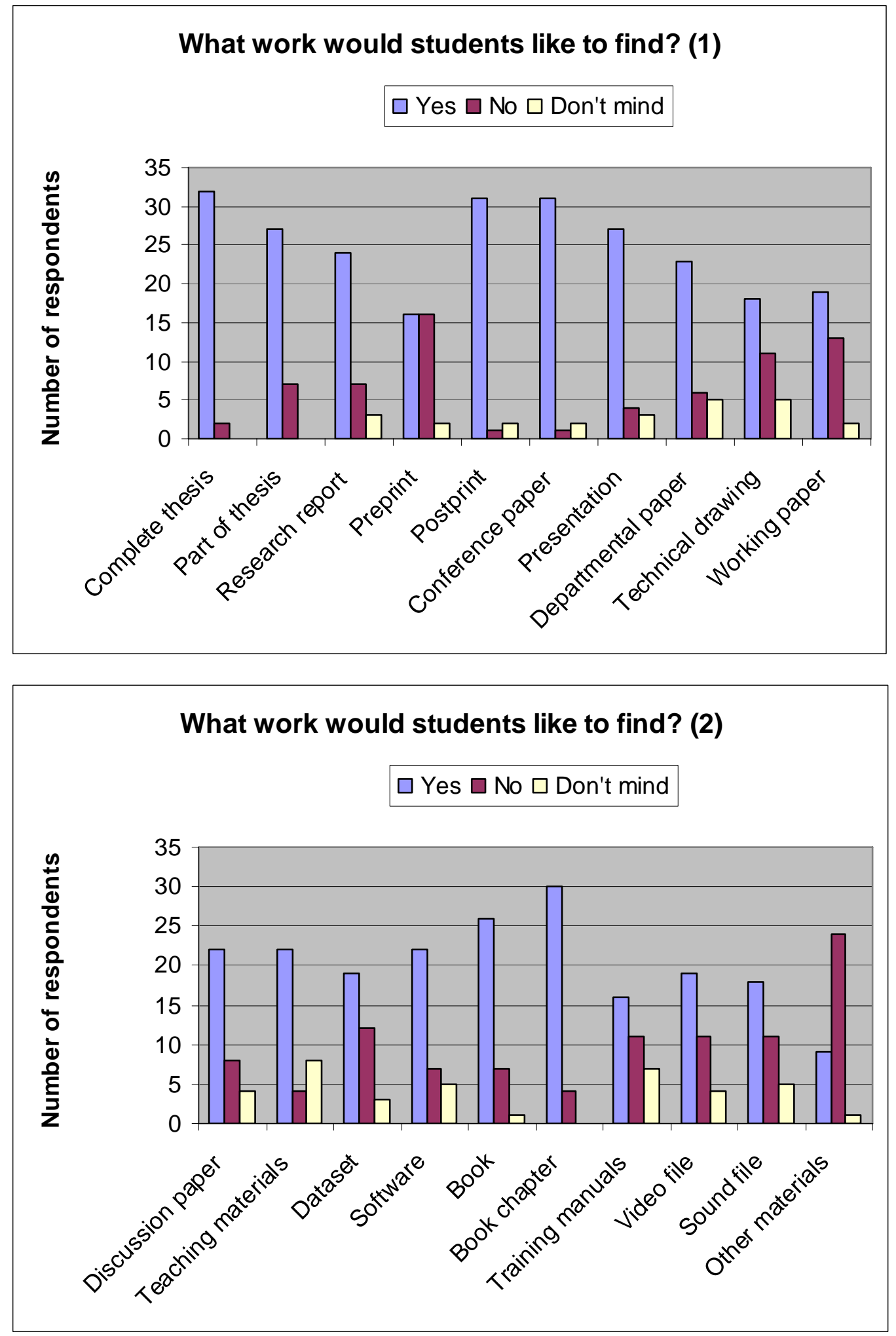

The most wanted types of work are complete theses (32 or $94.1 \%$ of students said 'Yes'), postprints and conference papers (each with 31 or $91.2 \%$ 'Yes' responses) and book chapters $(30,88.2 \%)$. These are clearly the materials with 
which students are most familiar and which have the greatest credibility for them.

The only types of work wanted by less than half of the students are training manuals and preprints (both with only 16 (47.1\%) 'Yes' responses).

Preprints, working papers and datasets are the least wanted items, having 16 (47.1\%), 13 (38.2\% and 12 (35.3\%) 'No' answers respectively.

When asked what other materials they might like to find, students requested open source software, bibliographies, collections of web links, linked citations, images and technical or specialist glossaries. One student felt there should be some measure of quality on the work:

"it should have some verification as to whether it is refereed or not" (Research student 20 (Engineering)).

\subsubsection{Responsibility for tasks}

Students were presented with a list of ten tasks which might be involved in depositing work on the LR. They were asked to indicate whether each task should be the responsibility of the student or of the repository administrators. An 'either or both' category was permitted if necessary. The results are shown in Figure 5.10.

The chart shows a clear consensus over some of the tasks. All students agreed that it was their responsibility to provide an abstract of their work, and most (32 students, or $94.1 \%$ ) felt that they should also be responsible for key words. As one student said:

"these are normal tasks for producing a paper and therefore not extra work" (Research student 19 (Engineering)).

A few students were concerned over the standardisation of key words and felt that the repository administrator might be in a better position to achieve this. 
Figure 5.10. Responsibility for tasks involved in depositing work in the Loughborough Repository

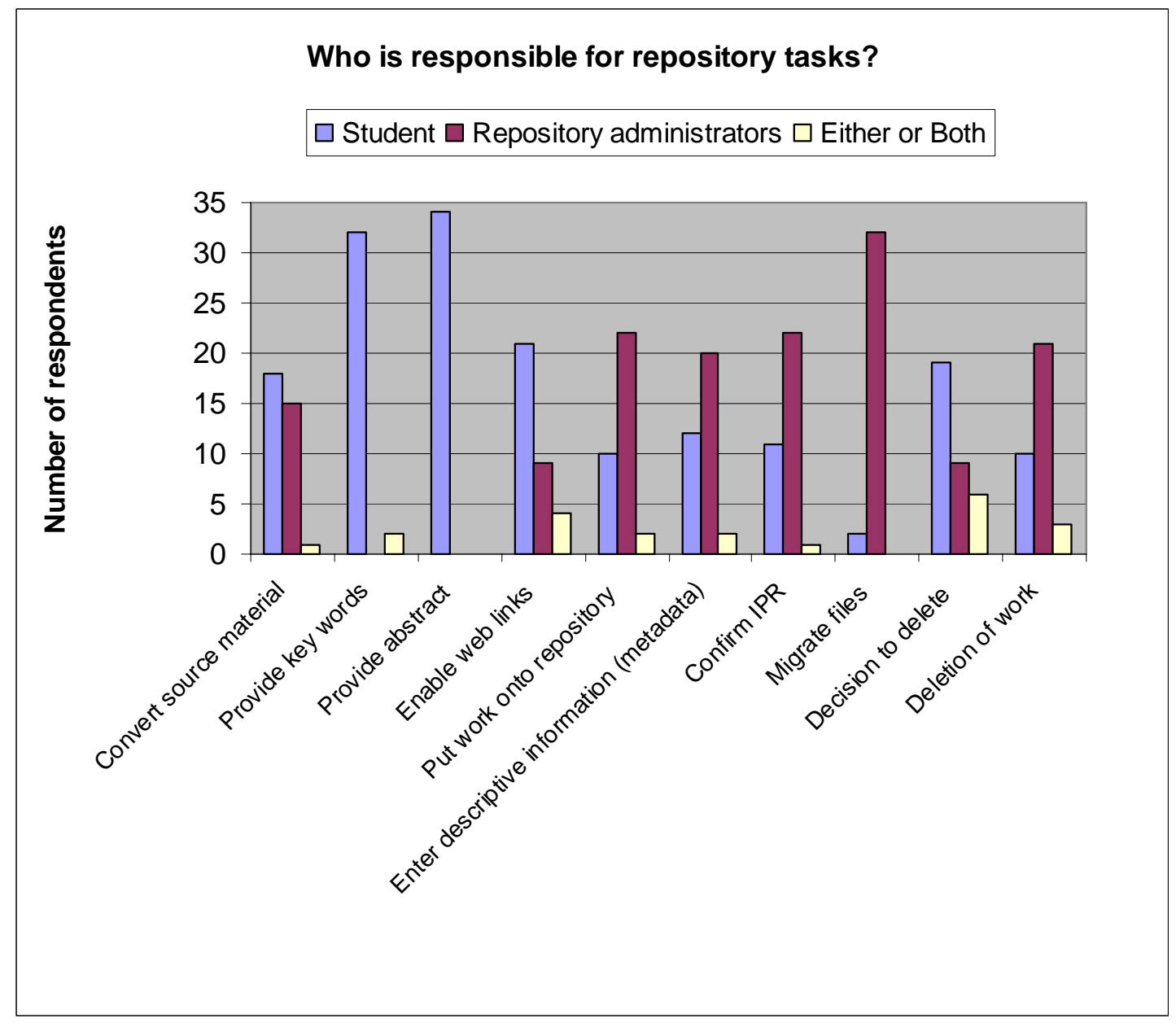

The other tasks for which students largely felt responsible were enabling web links (21 students, 61.8\%), and taking the decision to delete work $(19,55.9 \%)$. Students had mixed views about who should decide whether work should be deleted. Some felt that the repository administrators needed to have overall control so they could manage the use of space on their servers:

"if it has outlived its usefulness or need to make more space for others" (Research student 18 (Engineering))

Another stated:

"Once you have given it up there you sort of lose ownership, so it doesn't really matter" (Research student 19 (Engineering)).

Conversely, some students felt quite strongly that authors should retain the right to decide when their work should be deleted: 
"unless there was a legal or ethical reason to remove work" (Research student 23 (Science)).

Even those who chose the repository administrator for this task felt that they should be consulted prior to deletion.

Research students generally felt that the 'back end' tasks should be the responsibility of the administrators. Thus, 32 students (94.1\%) said that the repository administrators should be responsible for migrating files ('converting files to the latest version of hardware or software'); 22 students (64.7\%) agreed that the administrators should confirm intellectual property rights and actually put the work onto the repository; 21 (61.8\%) said they should be responsible for deleting material; and 20 (58.8\%) wanted the administrators to enter the descriptive information (i.e. metadata).

Some of the students' views were obviously coloured by their lack of knowledge or confidence in their abiility to perform the tasks. Several said that it depended on how complicated a task was. For example, regarding putting the work onto the repository:

"It depends on how difficult it is to put it on, how long it will take. It may be better for the repository administrator to do it to encourage more people to use it" (Research student 16 (Science))

or

"It depends how it operates. If it is a simple upload then the author, if the repository administrator has to see the work first, then they should do it" (Research student 11 (Engineering)).

Again, many thought that whilst they might be capable of performing a task such as entering descriptive information themselves, the administrators might make a better job of it:

"I would have my own descriptions, but the RA would probably do a better job of tying it in with other people's work" (Research student 26 (Science)).

However a few wanted nothing to do with it:

“I wouldn't want to have anything to do with putting it on in case I made a mess of it" (Research student 12 (SSH)). 
Students' views concerning the responsibility for intellectual property rights followed a similar pattern. A minority thought it should be their responsibility:

"its my work so I know more about this" (Research student 20

(Engineering)),

while others either felt they lacked the knowledge:

"I don't know enough about copyright" (Research student 12 (SSH)) or inclination:

“I couldn't be bothered" (Research student 17 (Engineering)).

\subsubsection{Mandating deposit}

Following Swan and Brown's example (Swan and Brown 2005, p.62), students were asked if they would comply if either the university or their research funders required them to self-archive their work. Their responses are displayed by faculty in Figure 5.11. A chi-square test was performed on these data.

Although the chi-square value of 7.257 is significant at the $5 \%$ probability level (with 2 degrees of freedom), the low expected counts in three of the cells render this statistic invalid. It is possible to see from the chart, however, that scientists and engineers appear to be much more willing to comply with a mandate to deposit than are social scientists and humanities students. No research students would refuse to comply.

Figure 5.11. Students views on complying with mandatory deposit

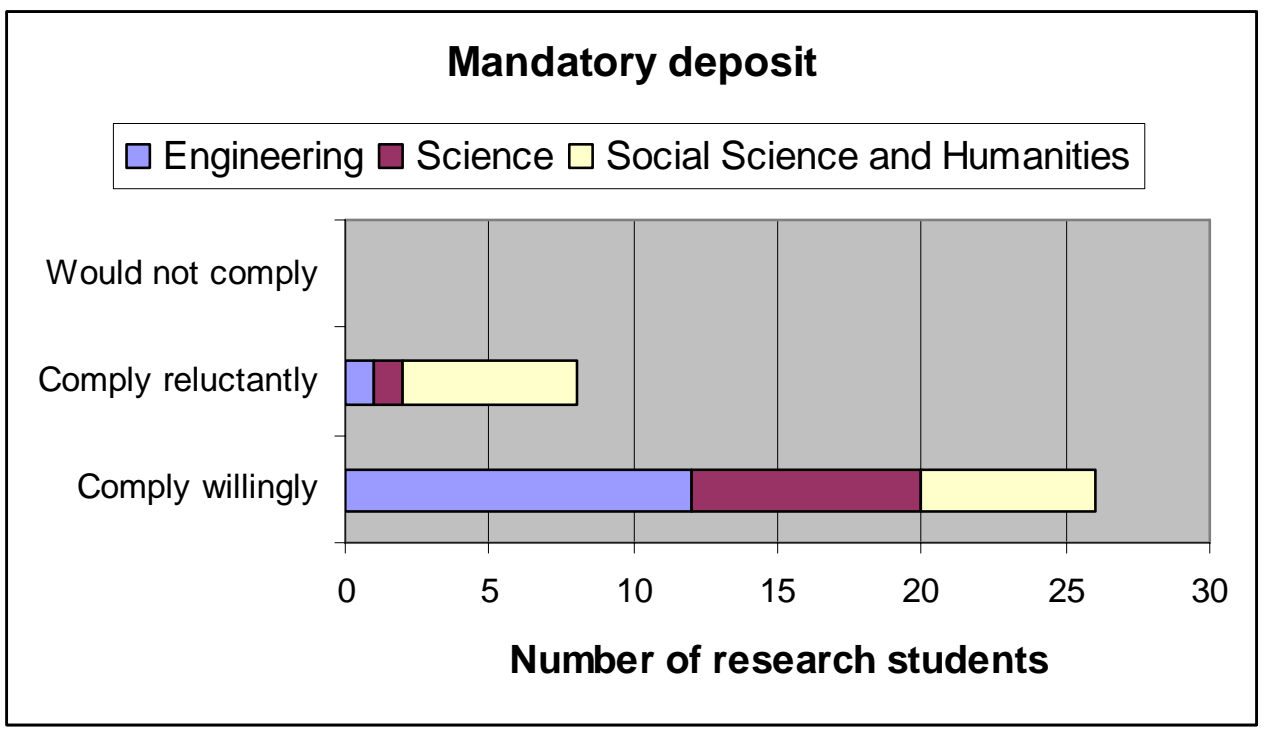


Many students were extremely positive about depositing their work. Some felt it was a moral obligation:

"I'm funded by public sector and that is research that should be open for the public to view it" (Research student 1 (Science))

"My work is funded by a charity - it deserves to be available to the public" (Research student 23 (Science)).

Others took a pragmatic view:

"ESRC want a copy anyway, it is no problem to put an electronic copy into the Loughborough repository" (Research student 2 (SSH)). "Your thesis is going to be available in the library - this just makes it easier for people to look at it" (Research student 16 (Science))

Some were enthusiastic about the opportunity to disseminate their work:

"It's a good thing to get your work known by more people. It's good for future research for other people to have access to your ideas. There's no sense keeping it a secret" (Research student 11 (Engineering)).

The dissenters gave various reasons. One was concerned about the confidentiality of his work. Two others felt that they should not be obliged to deposit their thesis work until they had completely finished with it. One student said he would be reluctant at least initially:

"because I want to take up a research fellowship which will extend the work into articles and maybe a book - I don't want anybody to take the ideas. It would perhaps be OK about 12-18 months after completion because then I will have already published" (Research student 29 $(\mathrm{SSH}))$.

One student had specific concerns about it. She agreed reluctantly "because of my worry over copyright and getting published in journals. Otherwise I would comply willingly" (Research student 13 (SSH)).

A few research students qualified their responses:

"if they helped me" (Research student 7 (Engineering), willingly) "as long as it is the final copy" (Research student 21 (SSH), willingly). 
Only one student objected on principle:

"It's a bit too dictatorial. Who owns the research? You shouldn't feel bullied into doing something you don't want to" (Research student 31 $(\mathrm{SSH})$ ).

\subsection{Attitudes toward depositing}

In the final part of the interview, students were invited to agree or disagree with a number of statements about their potential use of the LR. Some of these were classed as motivations to depositing (e.g. "I would deposit my work in the Loughborough Repository because I would like to get feedback or commentary from others"); others were deterrents (e.g. "I would be unhappy about depositing my work in the Loughborough Repository because I am afraid it might take too much time"). The complete list of statements can be seen in the interview schedule in Appendix 1. The statements were presented randomly to avoid any order effects, but the results are analysed here by type.

\subsubsection{Motivations}

Thirty-two cards showing motivation statements were presented. Students sorted these into 'agree' and 'disagree' piles, and then selected any that they particularly agreed with and ranked these in order of importance. The top five ranking statements were coded separately for the analysis.

In Figure 5.12 the statements are sorted according to the number of times they received a top five ranking, and then by the total number of 'agree' responses.

The chart shows clearly which are the most important motivations to the research students. Over one half of all the students (20 students, or 58.8\%) selected 'it is a good way of disseminating my work to the research community and beyond' as a top five (important) factor; moreover, eight of these students chose this as their number one motivation. Seventeen students (50\%) put 'to get feedback or commentary' in their top five, and 15 students (44.1\%) chose 'because I support the principle of open access'. Other frequently occurring top five factors are 'to share material with my research collaborators' (11 students, or $32.4 \%)$; 'if I was encouraged to do so by my supervisor' $(10,29.4 \%)$; 'to make my work available to other students' $(8,23.5 \%)$ and to 'gather information for career purposes' $(8,23.5 \%)$. 


\section{Figure 5.12. Motivations for depositing in the Loughborough Repository}

\section{Motivations for depositing}

$\square$ Agree (top 5 factor) $\square$ Agree $\square$ Disagree

Get feedback or commentary

Principle of OA Share with collaborators

Encouraged by supervisor

Available to other students

Gather information for career purposes

Available to others in university Establish priority / prove ownership

Available to myself

Work permanently available

Publish supplementary material

Encouraged by department

Publish quickly

Retain intellectual property rights

Practice for publishing elsewhere

Encouraged by research funders

Added services

Nominated departmental representative

Online instructions

Given training

Innovative technology

Collecting and organising work

Following others' example

Encouraged by co-author(s)

Encouraged by other students

Paid to deposit Informed of benefits

Easier to publish

Encouraged by library staff

Maintain multiple versions

Responsibility for preservation

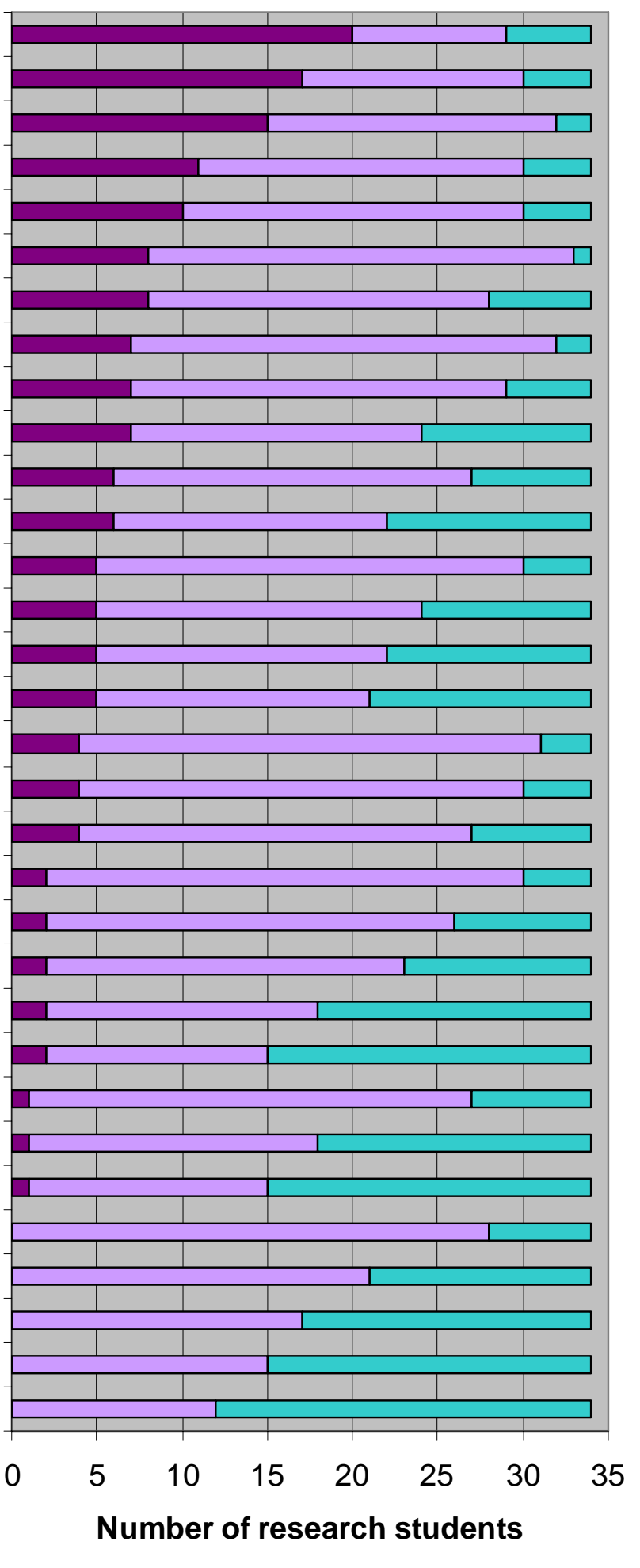


With over half the research students disagreeing, the most disagreed with statements were:

1. 'because I would like somebody else to take responsibility for preserving my work' (22 students disagreed, or 64.7\%)

2. 'because I would like to maintain multiple versions of my work' $(19,55.9 \%)$

3. 'if I was following the example of many others' (19, 55.9\%)

4. 'if I was paid to do so' $(19,55.9 \%)$

5. 'if I was encouraged to do so by library staff $(17,50 \%)$

Although interviewees were encouraged to share their thoughts as they allocated the statements to the different piles, most gave their full attention to deciding where to place each card and actually said very little.

\subsubsection{Deterrents}

The same procedure of selection and sorting, coding and ordering was undertaken for the deterrent statements. The results are shown in Figure 5.13.

Overall, many more students disagreed with the statements presented as deterrents. The greatest concerns were 'if I deposit my work in the Loughborough Repository I may not be able to publish it elsewhere later' (a top five factor for 17 students (55\%)); 'others might copy my work without permission' (11 (32.4\%)); 'other publishers owning the copyright of previously published material' (10 (29.4\%)); the risk of plagiarism (10 (29.4\%)) and 'my work is confidential' (9 (26.5\%)).

All 34 of the research students disagreed with the following two statements:

1. 'I would prefer to make my work available only on my personal website'

2. 'I would prefer to make my work available only on my departmental website'

Nearly all disagreed with these:

3. 'I would not want my work to be subject to a quality control process' (33 students disagreed, or $97.1 \%)$

4. 'I would not want my work to be deposited with work from other disciplines' $(32,94.1 \%)$

5. 'I am concerned about the long term feasibility of the repository' (32, 94.1\%)

6. 'I am concerned that my work might not be preserved in the long term' (32, 94.1\%) 


\section{Figure 5.13. Deterrents to depositing in the Loughborough Repository}

\section{Deterrents to depositing}

\begin{abstract}
Publication later elsewhere
Copying without permission

Publishers own copyright

Plagiarism

Confidentiality
\end{abstract}

Alteration without permission Mix with non-peer reviewed work

Change or delete work

Effect on journals publishers Storage capacity \& download time

Take too much time

Too broad readership

Few people see work

Technical skills

Prefer another repository

University's actions Low prestige

Move institution

University expects payment

Newness and small scale

Long term preservation

Effect on Learned Societies

Content too ephemeral

Long term feasibility

Mix with other disciplines

Quality control process

Prefer departmental website

Prefer own website

$$
0
$$

$\square$ Agree (top 5 factor) $\square$ Agree $\square$ Disagree

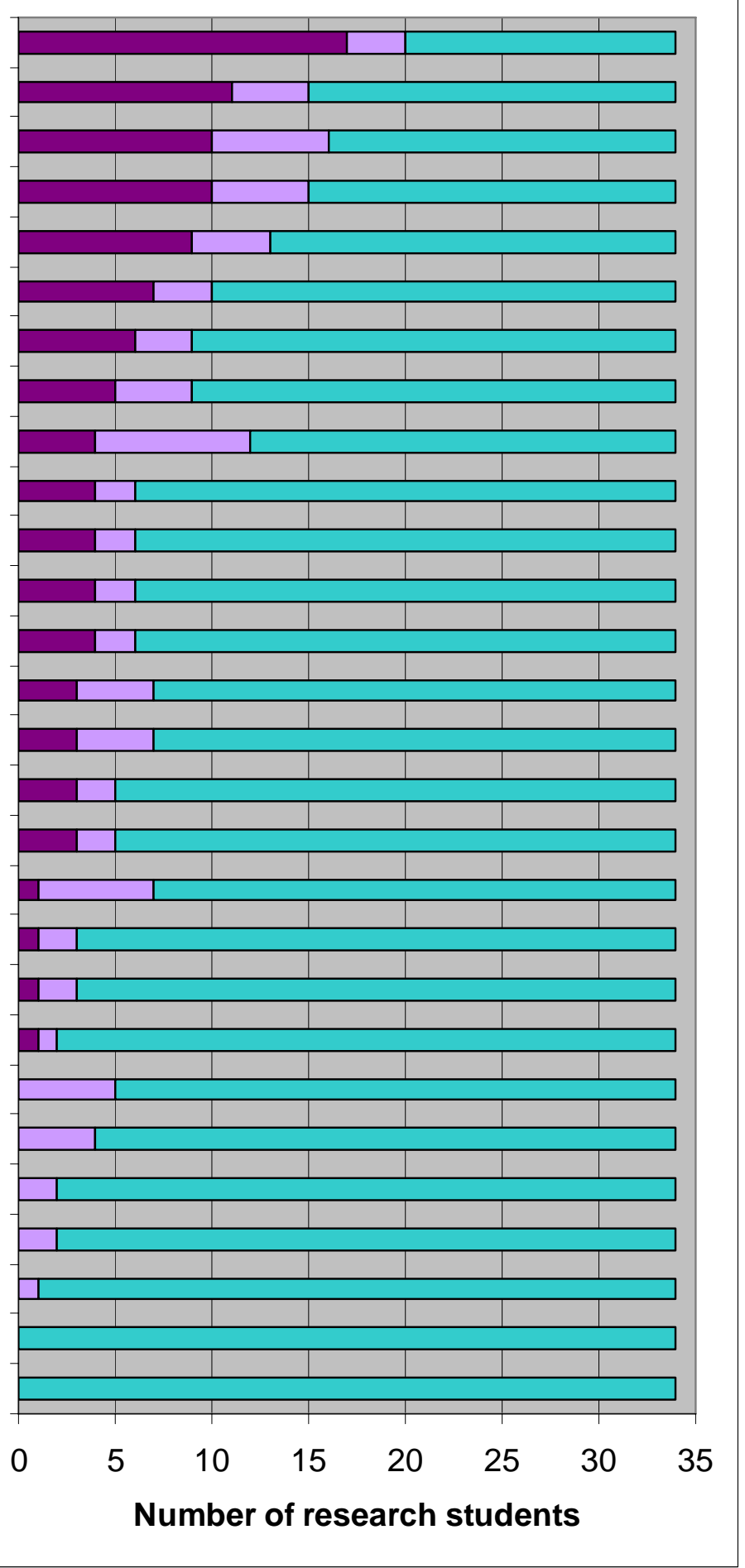


On the whole, research students were philosophical about depositing their work in the LR. For example, some recognised that work did not have to be in a repository to be at risk of alteration:

"but this could happen with any published work" (Research student 11 (Engineering), disagreed),

or plagiarism:

"but it can happen even with paid journals" (Research student 30 (Science), agree).

The long term feasibility of the repository was hardly a problem at all:

"If it goes down, it goes down - that's life" (Research student 28 (SSH), disagree),

nor was the 'newness' and initially small scale of the repository:

"It'll grow" (Research student 28 (SSH), disagree)

"That's going to change" (Research student 32 (SSH), disagree).

\subsection{The decision to deposit}

In the final question of the interview, research students were asked whether, on balance, they would deposit their work in the LR. Only one student said he would not.

\subsection{Conclusion}

The research students interviewed were interested in the project and fully engaged with the questions. In a number of cases the interview lasted much longer than the 30 minutes averaged for the pilot interviews. Given that the topic was unfamiliar to many of them, most very quickly grasped the core issues involved and came up with pertinent and useful comments.

In the next chapter, the students' views will be further discussed in the light of the findings from the repository managers' survey and the literature review. Together these will inform the recommendations made for the LR. 


\section{Chapter 6 Research students and institutional repositories - discussion}

\subsection{Introduction}

This dissertation has separately addressed the views of information professionals, academic authors, repository managers and research students. Now an attempt will be made to fulfil the aim of the project by synthesising these views into a coherent discussion of the role of the IR for research students, and vice versa. The chapter will first consider the position for research students as authors, then for students as users. It will finish with a discussion of some of the management issues that have been raised.

\subsection{Research students as authors: reasons for and against depositing work in an IR}

The interviews with research students explored at length their attitudes towards both OA publishing and IRs. Chapter 5 concluded with a consideration of factors which would motivate or deter students from depositing their work in a LR. Unlike many previous studies, an effort was made to get an understanding of the relative importance to students of the whole range of different factors. This culminated in the ranked lists shown in Figures 5.12 and 5.13. In this section an attempt will be made to explain some of these findings.

\subsubsection{Accessibility and impact}

The importance of dissemination and impact has been a recurring theme throughout this project. It has been shown that enhanced visibility of research output benefits both the institution (Section 2.2.1) and the individual (Section 2.3.1). By choosing the communication of results as their top reason for publishing (Section 5.2.3) and the dissemination of work as their most important motivating factor for depositing in the LR (Section 5.5.1), the findings from the research students unequivocally support this view. It is significant that seven of their eleven top ranked motivating factors relate to accessibility and impact (see Figure 5.12). 
In wanting to make their work available to others, the students are expressing similar views to those of the academic authors in Swan and Brown's studies (Swan and Brown 2004, p.220; Swan and Brown 2005, p.11). However, the reasons for wanting to disseminate their work are slightly different for the two groups. Academics want a high readership in a prestigious publication to increase their chances of being cited (Swan and Brown 2005, p.10), but research students are more motivated by the opportunity to get feedback and commentary (see Figure 5.12). Students are used to receiving feedback from their supervisors, colleagues and peers. They view it in a constructive way and use it to improve the quality of their work. Their relative lack of experience in research, coupled with their need for excellence in their theses, ensure that feedback and commentary from others in their field are highly valued.

Repository managers already recognise the importance to their potential depositors of dissemination and impact. Some have already used these as selling points in promoting their IR (Section 4.3.3). It is suggested that the opportunity for feedback should also be featured in IR advocacy.

\subsubsection{Rights}

Rights issues constitute the major deterrents to depositing. Concerns over publishing later elsewhere, others copying work without permission, the ownership of copyright, plagiarism, confidentiality and the alteration of work are students' top six ranked deterrents.

Again, these findings replicate those of other studies of academic authors (Section 2.4.8). Most of these concerns, however, may be addressed by appropriate user education. The risks of others copying, altering and plagiarising work are no greater for material deposited in an IR than for any other digital copy. Clearly it is essential that the IR has appropriate rights management software, and it is equally important that potential depositors are made aware of the protection this software offers.

Research students have several reasons for being concerned about the confidentiality of their work. Among those mentioned were:

- Restrictions imposed by research funders

- Restrictions arising from shared data collection 
- Ethical issues associated with sensitive personal information

- Professional protectiveness

However, these reasons do not apply to all students, nor to all their work. Authors must be encouraged to publish what they can on the IR, if necessary by anonymising or suppressing sensitive information.

Concern over the ownership of the copyright of previously published articles is reasonable, but again, it can be addressed. In the first instance, the SHERPA/RoMEO list of publishers' policies can be checked to establish whether the copyright holder is a 'green' publisher (Harnad 2004) and will therefore allow the publication of postprints on an IR. If not, Harnad recommends contacting the publisher directly to ask for permission to deposit the work. With some $90 \%$ of publishers being willing to allow deposit of postprints (Harnad 2005), this concern actually only applies to a minority of articles.

The top deterrent is, however, the effect of deposit on later publication (Sections 1.4 and 2.5.7). Given that their doctoral research is likely to provide the raw material for their first crop of published papers, the student may feel worried about jeopardising their chances of having a paper accepted if they 'pre-publish' it in an IR. There are several solutions to this:

- Check the target journal's policy before posting a preprint to the IR

- Select a target journal that will allow prior deposit in an IR

- Deposit only postprints in the IR

- Post an earlier or substantially different version of the article to the IR

- Use the IR as a place to deposit the type of work that cannot be published in a traditional journal

Finally, there is one rights-related factor that actually motivates authors to deposit their work in the IR. The opportunity to prove ownership and establish priority is ranked ninth in the list of motivations for research students. Even if the importance of this factor is discipline-dependent (Hubbard 2003, p.244; Section 2.3.3), it may nonetheless be promoted as a positive incentive to posting work to the IR.

\subsubsection{The principle of open access}

Swan and Brown have consistently found the principle of OA to be the most 
frequently given reason for publishing in an OA format (Swan and Brown 2004, p.220; Swan and Brown 2005, p.10) (Section 2.5.1). Nearly all the research students agreed with this philosophy, and almost half felt it was an important motivating factor. Their almost unanimous agreement that they would deposit their work in the LR bears this out (Section 5.6).

Appealing to this point of principle may be an effective way to encourage students and others to deposit their work in the LR.

\subsubsection{Influence of other people}

As far as research students are concerned, they are willing to be encouraged by their supervisors (ranked fifth), their department and their research funders to deposit their work in the LR. Encouragement from co-authors, fellow students and, least of all, library staff (ranked $30^{\text {th }}$ ), is not important to them.

This result clearly impacts on the likely effectiveness of advocacy by different parties. It suggests that while exhortation on the part of library staff is likely to go unheeded, encouragement to deposit from the supervisor may be very effective. Library advocates might therefore be advised to concentrate on convincing supervisors of the merits of the LR, and leave them to encourage their research students.

\subsubsection{Quality}

The present and future quality of OA material has been the subject of discussion in the literature (Section 2.5.6). Far from seeing the IR as an opportunity to get published more easily (ranked $29^{\text {th }}$ out of 32 in the list of motivations), many students were concerned about the quality of their own work (Section 5.4.1). Several commented that they would not want to deposit work that had not first been reviewed by their supervisor.

Nine students agreed with the statement 'I do not want to put my work with work that has not been peer-reviewed'. This demonstrates a misunderstanding of the way an IR operates. Several of the deterrents chosen by research students are based on misconceptions such as this (a small audience, broad readership and low prestige are examples).

This finding is perhaps a little unfair. Many students had no knowledge of 
repositories before the interview and were expected to give their opinions after relatively little discussion. Moreover, they were probably misled by the existence of these statements. The justification for including them was to establish what might worry users, so that those responsible for the LR can offer appropriate user education to relieve these concerns.

\subsubsection{Assistance with use}

User education and support will also be important in a practical sense. Although far from their top priority (and not normally selected as 'important' in the second phase of the interview), most students agreed that online instructions, training, and the availability of a nominated departmental representative, would motivate them to deposit their work. Conversely, the fear that they hadn't the technical skills necessary, or that the process of depositing would take too much time, were significant for a minority of students. The literature suggests these concerns are needless (Section 2.5.8), but one solution is to offer mediated deposit, either to struggling individual authors or for an initial start-up period. One IR manager goes as far as to suggest:

"secretarial support would be essential for getting an institutional archive off the ground and populated" (Respondent 13 (UK)).

From the email survey, it is clear that many of the managers of the more established repositories are already providing training sessions and instruction in using their repositories. Although this question was not directly asked, several mentioned workshops, seminars and training sessions in the context of promoting the repository (Respondents 5 (UK), 9 (UK), 10 (UK), 21 (Australia), 24 (UK), 25 (USA), 31 (Canada)). The impression gained is that, as a repository becomes more established, so the training needed to use it should be incorporated into regular research training programmes.

\subsubsection{Additional services}

That an IR offers services over and above those provided by conventional publishers is well recognised (Section 2.3.2). Students liked the idea of gathering information for career purposes ( $7^{\text {th }}$ in the list of motivating factors) and publishing supplementary material $\left(12^{\text {th }}\right)$. They did not see the role of the repository as encompassing version control $\left(31^{\text {st }}\right)$ or preservation $\left(32^{\text {nd }}\right)$.

Thirty of the students agreed that they would be motivated by the opportunity to 
'take advantage of added services such as download counts and crosssearching', but only four students felt this was particularly important to them. In common with user training, this underlines the distinction between what is 'nice to have' and what is really important. Thus added services may attract the attention of users (and therefore be helpful in promoting the repository), but what matters more are the core features of accessibility and rights.

\subsubsection{Longer term issues}

The importance of long term commitment and support for the IR from the institution has already been noted (Sections 2.4.3 and 2.4.5). Because of this, students were shown several statements relating to the permanence of their work in the repository. The long term feasibility of the repository, the transience of material and the preservation of their work did not concern most students. In fact, the ability to delete their work later was of greater importance to them.

Since deletion of material is not normally an option for a digital repository, there will again be a need for user education. Contributors should be encouraged to view deposit in the IR in the same way as publication in a journal or presentation at a conference - once the work is out there, it is there for good.

Of course, the control the institution has over an IR may render other options possible. For example, the institution may have different policies for different types of materials. Alternatively, a logically or physically separate repository may be maintained for temporary copies of working papers, thesis chapters or other work in progress. Temporary work may be automatically deleted after a set period, or there may be an option for the author to transfer it (with or without modifications) to permanent storage. This model replicates the facilities provided by subject repositories which permit the deposit of preprints and facilitate feedback and commentary (Section 2.3.3).

\subsubsection{Effect on others}

The only remaining high ranking factor to concern students is the effect of IRs on journals' publishers. Only four students chose this as an important deterrent to depositing in the LR, but nearly one third agreed with the statement. One student felt that OA publishing would negatively impact on journal quality, but most did not expand on their reasons for concern so it is difficult to know whether they feel that IRs are a threat to publishers (Section 1.4) or to 
scholarship.

\subsection{Research students as readers}

Most of students' previous experience of OA publishing has been in the role of reader. Whether aware of it or not, they have accessed OA material through search engines, subject gateways and other online pathways (Section 5.2.1). They are familiar with evaluating published material and they have firm ideas of what they want and need as readers.

Although not the main focus of this project, it is clear that students' experiences as readers are likely to colour their attitudes as authors.

In the middle part of the interview the students were invited to say which types of work they would like to find in the LR (Section 5.4.3). Unlike the RoMEO study which found that academics as readers were less demanding than academics as authors (Gadd et al. 2003c, p.171., Section 2.5.9), research students as readers generally wanted more from the repository than they themselves were willing to offer (Section 5.4.3).

\subsubsection{Electronic theses}

Complete theses were the type of work most sought after by research students as readers. The IR is in a unique position to make theses available online. Indeed, there are many IRs which either comprise only ETDs or have specialist ETD collections within a broader repository. Examples include the Digital Library of MIT theses <http://thesis.mit.edu/> , Boston College $<$ http://dissertations.bc.edu/>, Curtin University of Technology (Australia) $<$ http://adt.curtin.edu.au/theses/browse/by_author/all.html>, the University of Waterloo (Canada) <http://etheses.uwaterloo.ca> and the University of Edinburgh <http://www.era.lib.ed.ac.uk>.

For IR managers, there are a number of advantages in creating an ETD archive:

- Copyright in theses generally resides with the author or the institution and can easily be established. The rights problems associated with preprints and postprints do not apply.

- The status of theses is unambiguous. They are clearly neither preprints or postprints, but, having been through an examination process, their quality is 
guaranteed.

- Students can be mandated to deposit their theses (Section 2.4.1), thereby guaranteeing the growth of content.

- Complete copies of theses are unlikely to be easily available elsewhere. A relatively small proportion of printed theses are available outside of the host institution and the only alternative format is usually the microfiche. Inter library loans of theses are not encouraged. The increase in use of theses when made available electronically has already been noted (Section 4.2.2).

- There are ethical justifications for making theses available. Many research students are funded by public money, and their output should therefore be publicly available. (This is the justification for the recent statement by RCUK (Section 2.4.1)).

- The capability of the IR to store supplementary material such as data and results is a bonus.

With high demand for theses and relative ease of supply, ETDs should be a core part of any IR.

\subsubsection{Other types of material}

After theses, the types of material most wanted by research students are postprints, conference papers, book chapters, presentations, books and research reports (Figure 5.9). These are the types of work typically found on existing IRs (Swan and Brown 2005, p.58). Again, the IR is uniquely positioned to make these available to a wide audience. Presentations, research reports and even conference papers are otherwise often inaccessible to anyone other than the original target audience.

\subsection{Research student use of the IR: management issues}

In addition to directly answering the questions in the email survey, IR managers highlighted some other important matters. The issues most relevant to research students are discussed below.

\subsubsection{Policy}

Many of the repositories surveyed had not long been in existence. As a result, their policies and procedures for accepting material were not fully established. Although, as individuals, the managers were positive about research student 
involvement, from the institutional point of view, students' work was often not a high priority. In the early days it is usually the academic authors that are targeted first.

However, the very fact that policies have not been confirmed provides an opportunity for the interests of research student to be considered. This should be encouraged.

\subsubsection{Repository organisation}

There are two options for structuring IR content in the IR: by document type or by subject area. The IRs surveyed included examples of both. ETD repositories have already been discussed (Section 6.3.1); other repositories limit content to peer-reviewed, published research articles (Respondent 5(UK)), work published by the university (Respondent 22 (USA)), or to records based on bibliographic material (Respondent 7 (UK)). They organise this material by subject, department or other topical grouping.

To a certain extent the content and structure of a repository is influenced by the software controlling it. Thus 'communities and collections' are core to the DSpace software (to be used in the LR), while Eprints software allows browsing by year, format or department (e.g. Durham University e-prints: $<$ http://eprints.dur.ac.uk/>. Both are user-configurable.

The relative merits of the different types of software are important, but not the focus of this project. The significant issues are whether the software facilitates differentiation of different types of material - either by document type (thesis, published research paper etc) or by its subject area - and whether research student output can be accommodated by this structure.

\subsubsection{Quality}

Everybody agrees that quality is important (Sections 2.2.1, 2.5.6 and 5.4.3). Those responsible for IRs have taken various approaches to ensuring the quality of content (Section 4.2.3), but there is still ongoing concern about the issue, especially regarding student work.

One IR manager summed up the problem as follows:

"There is some concern about adding material that is below the standard 
set for $\mathrm{PhD}$ thesis or scholarly articles. Even with an explanation about the content, search engines may bring users directly to a document and users may miss the explanation that the material is student output. It's my own opinion that most users are more savvy than this and have responsibility to use information appropriately. I think the positives of including student output in institutional repositories far outweighs the negatives, but I know that opinion is not universally shared amongst my colleagues." (Respondent 28 (USA)).

Another IR manager also mentioned the difference in outlook between academics and information professionals:

"One of the things that I have discovered throughout this project is that LIS staff are far keener to open up access to certain pieces of information than the academics. We see it as disclosure of information within, of course, the legal restraints, but the academics are far more concerned about quality. So LIS staff would like to include preliminary drafts of parts of theses, research papers by students, research seminars by students, but this still seems to be a bridge too far for academics" (Respondent 29 (USA)).

It is important that the institution's quality standards are respected, but also that whatever criteria are applied when regulating content are applied fairly to research students' work.

\subsubsection{Single or multiple repositories}

One way of satisfying both the academics' desire for 'quality' and the information professionals' inclination towards inclusiveness is to maintain separate collections for refereed and non-refereed material (Section 4.4.2). These collections may be stored together in a single repository, or separately in multiple repositories. A number of institutions maintain several repositories, among them the University of Nottingham <http://eprints.nottingham.ac.uk/>, The University of Pittsburgh <http://www.library.pitt.edu/articles/digital.html>, and the California Institute of Technology (Caltech Collection of Open Digital Archives, <http://library.caltech.edu/digital/>. Presumably the benefit of separate repositories is felt mainly by those who browse the collections via the repositories' native interfaces. Researchers who access repository content via external search engines are not immediately aware of the provenance of the 
work.

\subsubsection{OAI Harvesting}

A major advantage of depositing work in an IR compared with posting it to an individual or institutional website is that the former is potentially OAI compliant and therefore visible to both internet search engines and OAI service providers (Sections 1.3, 2.3.1 and 2.3.4). Several of the IR managers commented that their content was being harvested by Google (Respondents 5 (UK), 10 (UK), 16 (USA) and 18 (USA)). Although many information professionals might prefer students to start their searches for information in the high quality (and expensive) subscription databases, most students will at some point try searching with Google or another search engine (Section 5.2.1). It is therefore an advantage to research students both as authors and as readers to have good quality content in an externally accessible IR.

\subsection{Conclusion}

This chapter has drawn together the views of research students and IR managers, and compared these with other findings from the literature. There have been many points of agreement. It can be concluded that the needs of research students are not significantly different from those of other IR users, but that in many cases these needs are not yet recognised. In the final chapter some recommendations will be made to restore the balance. 


\section{Chapter 7 Research students and the Loughborough Repository - conclusions and recommendations}

\subsection{Introduction}

This study is unique in explicitly considering the role of research students in using an IR. In this final chapter, some of the limitations of the study will be outlined, some recommendations for the LR will be offered, and some suggestions will be made for further research. The chapter concludes with an assessment of whether the project has achieved its aim and objectives.

\subsection{Limitations of the study}

\subsubsection{Research students interviews}

Time constraints limited the number of research student interviews that could take place, and indirectly, the type of analysis which could then be performed. Ideally, many more students would have been interviewed. A larger representative sample would have enabled further quantitative analysis (including valid tests for significance) and a more useful comparison of the three faculties.

At the detailed level, the interview schedule worked well and appeared to be enjoyed by many of the research students. This was fortunate, because it frequently exceeded the planned interview time. If the study were repeated, it might be more useful to reduce the interview time by the following means.

- Change these into closed questions:

o Question 1.2, finding information.

o Question 1.3.2, prior experience of publication.

o Question 3.2, file formats in the IR. Be more specific, naming proprietory products where necessary. Also, ask the students separately about the file formats they use and the file formats they wish to deposit. This would remove any ambiguity caused by the nature of the question.

- Reduce the number of elements in Question 3.4 (responsibility for tasks). 
The two tasks involving the deletion of work should be omitted. Deletion of work is not common practice in repositories and the inclusion of these elements may have created a misleading impression later in the interview.

- Reconsider the format of Part 2 on OA publishing. This entire section was valuable in provoking discussion of OA publishing and digital repositories, and as such it merits inclusion. However, the data gathered here did not prove to be as useful as expected. Students' experience of digital repositories was generally very limited.

Leaving aside these minor changes, and given the fixed time scale and resources, the methodology chosen was on balance extremely successful. The interviews elicited an enormous amount of high quality, credible and useful information.

\subsubsection{IR managers survey}

The response to the email survey greatly exceeded expectations. The response rate was excellent and many IR managers clearly gave great thought to their answers. Two minor changes could be made:

- Clarify the meaning of 'research students' for the non-UK managers. Most respondents had no difficulty with this term, but one manager queried its meaning.

- Re-phrase the first question to make it clear that a quantitative assessment of the amount of use made of the IR by research students was not expected. (Interestingly, the American respondents appeared to be more concerned about not providing numerical data than their British counterparts).

Regarding further changes, there is a risk that if additional information was required, the busy managers would be less inclined to respond, or their answers would be less detailed. However, if this risk could be avoided, some additional questions could be asked. These are listed below.

Policy:

- Who is responsible for IR policy at your institution, and is there a policy for research students' work?

- Who decides which material is acceptable in the repository?

- Are undergraduate theses and dissertations welcome in your IR? 
Quality:

- Should the work of research students be refereed before deposit? e.g. by their supervisors?

Organisation:

- How is your repository structured?

- What type of material is contained in the repository and how useful is it to research students as readers?

- Should research student output be stored in the same or a separate repository to other material?

\subsection{Recommendations}

The following recommendations are made to those responsible for the LR.

\subsubsection{Repository content}

IR administrators should encourage the deposit of all types of material. If this is not feasible, as a minimum the following types of material should be permitted in the repository:

- Theses

- Postprints

- Conference papers

- Book chapters

These are among the most acceptable formats for both authors and readers.

The following file formats are favoured by research students, and an upgrade (migration) path for these should be provided:

- PDF

- Word processed documents

- Presentations

- HTML

- Images

- Spreadsheets

For the generic file formats listed above (e.g. Word processed documents) there should be a recommended IR standard (e.g Microsoft Word). If there are 
likely to be rights problems with the long term storage of files created using proprietory software, then a straightforward procedure should be available for converting these document types to copyright free formats. Authors should be able to perform any conversion procedures themselves.

\subsubsection{Organisation of the repository}

Two schemes are recommended for organising the LR. The first is by subject area (say, by faculty and department), and the second is by the type of material (e.g. theses, unpublished and pre-published material). Full use should be made of Dspace 'communities' and 'collections' to separate material in these ways.

Irrespective of the structure chosen, the following are important:

- The LR should be fully OAI-PMH compliant, and registered for harvesting by key service providers (including Google Scholar).

- However an article is located (whether by browsing or key word search), its provenance should be made clear to the reader. As a minimum, the repository record should contain an indicator showing whether the work has been refereed or not; if possible, the file properties should contain a textual description of the origin and type of the work.

- The LR should support the rights of authors under the Creative Commons licensing scheme.

\subsubsection{Intellectual property rights}

Enable authors to make an informed decision:

- Provide online help in the form of answers to FAQs covering the following areas:

o the ownership of copyright

o protecting your rights using Creative Commons licensing

0 the implications of depositing material for subsequent publication (including how to avoid future problems (Section 6.2.2)

o plagiarism

o file security

- Provide a link to the SHERPA/RoMEO list of journals' publishers' selfarchiving policies <http://romeo.eprints.org/>

\subsubsection{Providing added value}

The provision of added value services will give users an extra incentive both to 
deposit their work and to search for material on the repository. The benefits of these services should feature in promotional activities.

Added value services most likely to be popular with authors include:

- personal, departmental or institutional publication lists

- mediated upload for the nervous or the time-constrained

- standardisation of metadata, especially key words

- impact indicators such as hit counts on papers, download statistics and citation analyses

Added value services for readers include:

- 'quality' indicators (i.e. a clear statement regarding the status of material preprint, postprint, working paper, thesis etc)

- browseable subject-based communities

- publication of supplementary material

- links to cited material

- cross-searching of internal and external repository collections.

\subsubsection{User education and training}

User education is essential. It serves to instruct, inform and persuade university members of the benefits of the IR. Some options for providing education and training include:

For authors:

- Standalone training sessions covering the process and procedures for depositing work. There should be appropriate links to information about these sessions on the library's web site and on the library's pages on the Learn server.

- Context sensitive help during the upload process.

For readers:

- Inclusion of the LR as a resource in existing user education sessions for both postgraduate students and staff members.

- Instruction in the use of search engines covering OA material, for example those of service providers such as OAIster <http://oaister.umdl.umich.edu/o/oaister/>, ARC <http://arc.cs.odu.edu/> and e-prints UK <http://eprints-uk.rdn.ac.uk/search/>. 
For both authors and readers:

- Online help pages

- Downloadable user instructions

- Printed fact sheets

User education should cover:

- the practical issues of depositing and accessing work

- the benefits of using the LR

- the possible risks involved with depositing work, and how to avoid them.

\subsubsection{Promotion and advocacy}

The purpose of advocacy is to promote the motivations for using the IR and reassure users who may be worried about the deterrents.

Promotion of the repository should begin with internal marketing to library staff with a view to gathering a team of enthusiastic IR advocates.

Possible mechanisms for promotion and advocacy include:

- Seminars and presentations

o to university management, academic staff and students

0 in the library and in departments

o dedicated, or as part of general library promotion.

- Leaflets, posters, newsletters and other printed literature.

- Links from library web pages, including a link to the repository home page from the library home page, as well as appropriate links from the library catalogue to individual items. The LR should be incorporated as a database within Metalib and added to all subject categories.

- Targeted emails to opinion leaders (e.g. senior academics)

- Email updates and reminders as content increases.

The following should feature in promotional activity:

- the principle of open access

- the opportunity to disseminate work

- the opportunity to receive feedback

- the potential for increased citation rate and impact 
Advocacy activities should be directed firstly at academic staff, and then, with their help, to research students. Targeting individual departments may be the most efficient approach.

\subsubsection{Staffing}

In addition to the technical staff necessary to set up the repository and create and update supporting web pages, the LR should be sufficiently resourced with trained staff in the areas of:

- Checking intellectual property rights

- Collection and identification of bibliographic data

- Metadata creation

- User education and training

- Advocacy

The experience of other repositories is that the workload associated with implementing a repository always exceeds expectations.

\subsubsection{Conclusion}

Above all, it is important that IR management work collaboratively with university members, including research students, academic staff, IT services and senior management, to ensure the IR is accepted and valued.

\subsection{Directions for future research}

This project could develop in a number of ways. Some possibilities are listed below.

Exploring the attitudes of research students:

- Extend the survey to include many more students from existing and additional subject areas. Some key areas (such as Maths and Computer Science) were omitted from the research in order to avoid conflict with other locally ongoing projects; other potentially interesting disciplines are not represented at Loughborough University (especially arts related subjects). Three larger samples of more contrasting subject areas would be appropriate. Larger samples would also permit some analysis by other variables (age, gender etc.)

- Use the same interview schedule with academic staff and compare their 
responses with those of the students. A comparison of the matched responses of research students and their supervisors might be interesting.

- Repeat the interviews after a year or so, when people will be generally better informed about OA publishing and the LR. Compare the results with this early study.

- Extend the survey to cover the deposit and use of non-research material, for example, teaching and learning material, administrative documents etc.

- Investigate the conditions under which people may deposit work. This was loosely covered in the motivation statements, but would benefit from more detailed consideration.

The views of IR managers:

- Extend the IR managers survey to others involved with IRs. The views of people specifically responsible for implementation or for advocacy would be interesting.

- Further extend the survey by posting questions to a relevant online discussion list (for example the DSpace discussion list suggested by Respondent 14 (USA)).

- Interview IR managers in person. Much could be learned from face-to-face talks with experienced IR managers.

Generally:

- Examine the longer term issues of depositing work. The vast majority of research students are on fixed term contracts and are likely to move away from Loughborough when they finish their doctorates. What are the implications for the LR of an author's move to a different institution? The whole issue of preservation merits significant attention.

- Investigate methods for differentiating between peer reviewed and non-peer reviewed material when it is accessed externally (e.g. when an item is located by a search engine and the work is viewed out of context).

- Explore ways of measuring the use of IRs by students as readers. 


\subsection{Conclusions}

The overall aim of this project was to 'explore and assess the value of the LR to research students'. The objectives were:

1. To explore previous research into the attitudes and motivations of academic authors, particularly with respect to OA publishing.

2. To establish the potential role of research students regarding the LR - both as contributors and as users of information.

3. To compare interdisciplinary differences in research students' attitudes toward the LR.

4. To investigate the role played by research students in more established IRs at other universities.

5. To use the findings of the project to make appropriate recommendations to the managers of the LR.

All but the third objective have been achieved. The views of both students and repository managers have been sought, described, analysed and discussed at length. Only the issue of inter-disciplinary differences remains inconclusive. Either the small sample of students interviewed is representative of the total student population, and there are few significant differences between the faculties; or the sample is not representative and further work is required. 


\section{References}

Antelman, K., 2004. Do open-access articles have a greater research impact? College and Research Libraries [online], 65(5) , 372-382.

$<$ http://www.lib.ncsu.edu/staff/kantelman/do_open_access_CRL.pdf>, [accessed 26.05.05].

Ayris, P., 2001. Open archives: institutional issues. Vine, 125, 34-37. $<$ http://oberon.emeraldinsight.com/...>, [accessed 16.06.05].

Banks, P., 2004. Open access: a medical association perspective. Learned Publishing [online], 17(2), 135-142. <http://docserver.ingentaconnect.com/...>, [accessed 27.05.05].

Baudoin, P. and Branschofsky, M., 2004. Implementing an institutional repository: the DSpace experience at MIT. Science and Technology Libraries, 24(1/2), 31-46.

Berry, R.S., 2000. 'Full and open access' to scientific information: an academic's view. Learned Publishing [online], 13(1), 37-42.

<http://puck.ingentaconnect.com/...>, [accessed 16.06.05].

Bruce, R., 2005. JISC. Focus on Access to Institutional Resources (FAIR) Programme. < http://www.jisc.ac.uk/index.cfm?name=programme_fair>, [accessed 13.06.05].

Carr, L. and Harnad, S., 2005. Keystroke economy: a study of time and effort involved in self-archiving.

<http://eprints.ecs.soton.ac.uk/10688/01/KeystrokeCosting-publicdraft1.pdf>, [accessed 28.06.05].

Cervone, H.F., 2004. The repository adventure. Library Journal [online], 129(10), 44-46. <http://proquest.umi.com/...>, [accessed 31.05.05].

Chan, L. et al., 2002. Budapest Open Access Initiative. ARL Bimonthly Report [online], 220. <http://www.arl.org/newsltr/220/boai.html>, [accessed 13.06.05]. 
Cozzarelli, N.R. et al., 2004. Results of a PNAS author survey on an open access option for publication. PNAS [online], 101(5), p.1111.

<http://www.pnas.org/cgi/reprint/101/5/1111>, [accessed 16.06.05].

Crow, R., 2002. The case for institutional repositories: a SPARC position paper. <http://www.arl.org/sparc/IR/IR_Final_Release_102.pdf>, [accessed 26.05.05].

Day, M., 2003. Prospects for institutional e-print repositories in the United Kingdom. <http://www.rdn.ac.uk/projects/eprints-uk/docs/studies/impact/>, [accessed 16.06.05].

De Beer, J.A., 2005. Open acess scholarly communication in South Africa: current status, significance, and the role for national information policy in the national system of innovation. MPhil dissertation, Department of Information Science, Stellenbosch University (South Africa).

<http://eprints.rclis.org/archive/00003922/01/DeBeerJenniferMThesisFinal.pdf>, [accessed 24.06.05>

Denscombe, M., 2003. The good research guide for small-scale social research projects. $2^{\text {nd }}$ ed. Maidenhead: Open University Press.

Drake, M.A., 2004. Institutional repositories: hidden treasures. Searcher [online], 12(5), 41-45. <http://www.infotoday.com/searcher/may04/drake.shtml>, [accessed 31.05.05].

Eprints.org, 2004. Self-archiving FAQ for the Budapest Open Archives Initiative. $<$ http://www.eprints.org/self-faq/ >, [accessed 06.06.05].

Falk, H., 2004. The revolt against journal publishers. The Electronic Library [online], 22(2), 184-187. <http://ceres.emeraldinsight.com/...>, [accessed 27.05.05].

Foster, N.F. and Gibbons, S., 2005. Understanding faculty to improve content recruitment for institutional repositories. D-Lib Magazine [online], 11(1). <http://www.dlib.org/dlib/january05/foster/01foster.html>, [accessed 26.05.05]. 
Gadd, E. et al., 2003a. RoMEO studies 1: The impact of copyright ownership on author-self-archiving. Journal of Documentation [online], 59(3), 243-277.

$<$ http://iris.emeraldinsight.com/...>, [accessed 13.06.05]

Gadd, E. et al., 2003b. RoMEO studies 2: How academics want to protect their open access research papers. Journal of Information Science [online], 29(5), 333-356. <http://psea1.swetswise.com/...>, [accessed 27.05.05].

Gadd, E. et al., 2003c. RoMEO studies 3: How academics expect to use openaccess research papers. Journal of Librarianship and Information Science [online], 35(3), 171-187. <http://psea1.swetswise.com/...>, [accessed 27.05.05].

Gadd, E. et al., 2004. RoMEO studies 6: Rights metadata for open archiving. Program [online], 38(1), 5-14.

<http://eprints.rclis.org/archive/00001431/01/Romeo_Studies_6.pdf>, [accessed 26.05.05].

Genoni, P., 2004. Content in institutional repositories: a collection management issue. Library Management [online], 25(6/7), 300-306.

<http://thesius.emeraldinsight.com/...> , [accessed 26.05.05].

Gillham, B., 2000. The research interview. London: Continuum.

Gorman, G.E. and Rowland, F., eds., 2004. International yearbook of library and information management 2004-2005: Scholarly publishing in an electronic era. London: Facet.

Hajjem, M.C. and Harnad, S., 2005. Accès libre aux articles scientifiques et mouvement d'auto-archivage à l'QUAM.

<http://www.crsc.uqam.ca/lab/chawki/Auto-archivaeuqam.pdf>, [accessed 24.06.05].

Hall, D.G., 2003. Some thoughts on journal publishing in the $21^{\text {st }}$ century. Optics and Photonics News [online]. October 2003, 30-33. <http://www.osaopn.org/...>, [accessed 29.08.05]. 
Harnad, S., [2003?]. Open online access to the refereed journal literature. In: Welcome: American Scientist Open Access Forum, SIGMAXI.ORG, 16 June 2005, 12:22:13 -0400 GMT.

Harnad, S., 2005. Journal Publishing and Author Self-Archiving. American Scientist Open Access Forum, SIGMAXI.ORG, 25 August 2005, 17:25:44 +0100 GMT.

Harnad, S. et al., 2003. Mandated online RAE CVs linked to university eprint archives: enhancing UK research impact and assessment. Ariadne [online], 35(April 2003). <http://www.ariadne.ac.uk/issue35/harnad/>, [accessed 19.06.05].

Harnad, S. et al., 2004. The Access/Impact Problem and the Green and Gold Roads to Open Access. Serials Review. Serials Review [online], 30(4), 310-314. <http://eprints.ecs.soton.ac.uk/10209/01/impact.html>, [accessed 26.08.05].

Heery, R. and Anderson, S., 2005. Digital repositories review. UKOLN. <http://www.jisc.ac.uk/uploaded_documents/rep-review-final-20050220.pdf>, [accessed 30.06.05].

Hey, J., 2004. Targeting academic research with Southampton's institutional repository. Ariadne [online], 40(July 2004).

$<$ http://www.ariadne.ac.uk/issue40/hey/>, [accessed 26.05.05].

Horwood, L. et al., 2004. OAl compliant institutional repositories and the role of library staff. Library Management [online], 24(4/5), 170-176.

$<$ http://iris.emeraldinsight.com/...>, [accessed 26.05.05].

Hubbard, B., 2003. SHERPA and institutional repositories. Serials [online], 16(3), 243-247. <http://uksg.metapress.com/...>, [accessed 26.06.05].

Hunt, C., 2001. Archive user survey.

<http://www.eprints.org/results/FinalReport.doc>, [accessed 24.06.05].

Kaser, D., 2003. The politics of open access. Information Today [online], 20(11), p.16. <http://proquest.umi.com/...>, [accessed 27.05.05]. 
Kurtz, M.J., 2004. Restrictive access policies cut readership of electronic research journal articles by a factor of two.

<http://opcit.eprints.org/feb19oa/kurtz.pdf>, [accessed 20.06.05].

Lamb, C., 2004. Open access publishing models: opportunity or threat to scholarly and academic publishers? Learned Publishing [online], 17(2), 143150. <http://docserver.ingentaconnect.com/...>, [accessed 26.05.05].

Lawrence, S., 2001. Online or invisible? Nature [online]. 411(6837), p.521. <http://citeseer.ist.psu.edu/online-nature01/>, [accessed 29.08.05].

Leung, S.W., 2005. International conference on developing digital institutional repositories: experiences and challenges. Library Hi Tech News [online], 22(2), 14-15. <http://puck.emeraldinsight.com...>, [accessed 16.06.05].

Lynch, C.A., 2003. Institutional repositories: essential infrastructure for scholarship in the digital age. ARL Bimonthly Report [online], 226, 1-7. <http://www.arl.org/newsltr/226/ir.html>, [accessed 05.06.05].

Mackie, M., 2004. Filling institutional repositories: practical strategies from the DAEDALUS project. Ariadne [online], 39(April 2004).

<http://www.ariadne.ac.uk/issue39/mackie/>, [accessed 06.06.05].

Mark Ware Consulting, 2004. Publisher and Library/Learning Solutions (PALS). Pathfinder research on web-based repositories: Final report. Bristol: Mark Ware Consulting Ltd. <http://www.markwareconsulting.com/>, [accessed 16.06.05].

Morris, S., 2003. Open publishing. Learned Publishing [online], 16(3), 171-176. $<$ http://docserver.ingentaconnect.com/...>, [accessed 27.05.05].

Morris, S., 2004. Open access: how are publishers reacting? Serials Review [online], 30(4), 304-307. <http://www.sciencedirect.com/...>, [accessed 27.05.05]. 
Peters, T.A., 2002. Consortial speaking. Digital repositories: individual, discipline-based, institutional, consortial, or national? The Journal of Academic Librarianship [online], 28(6), 414-417. <http://www.sciencedirect.com/...>, [accessed 16.06.05].

Pinfield, S., 2001. How do physicists use an e-print archive? Implications for institutional e-print services. D-Lib Magazine [online], 7(12). <http://www.dlib.org/dlib/december01/pinfield/12pinfield.html>, [accessed 16.06.05].

Pinfield, S., 2002. Creating institutional e-print repositories. Serials [online], 15(3), 261-264. <http://uksg.metapress.com/...>, [accessed 16.06.05].

Pinfield, S. et al., 2002. Setting up an institutional e-print archive. Ariadne [online], 31. < http://www.ariadne.ac.uk/issue31/eprint-archives/intro.html>, [accessed 13.06.05].

Pinfield, S., 2003. Open archives and UK institutions. D-Lib Magazine [online], 9(3). <http://www.dlib.org/dlib/march03/pinfield/03pinfield.html>, [accessed 16.06.05].

Pinfield, S., 2004. Self-archiving publications. In: Gorman, G.E. and Rowland, F., eds. International yearbook of library and information management 20042005: Scholarly publishing in an electronic era, pp.118-145.

Project RoMEO, 2003.

<http://www.Iboro.ac.uk/departments/ls/disresearch/romeo/>, [accessed 13.06.05]

Prosser, D.C., 2004. From recommendations to practice - the next steps towards open access. Sconul Focus [online], 32(Summer/Autumn), 24-27. <http://www.sconul.ac.uk/pubs_stats/newsletter/32/9.rtf>, [accessed 16.06.05].

Research Councils UK, 2005. News release: 28 June 2005. RCUK announces proposed position on access to research outputs.

<http://www.rcuk.ac.uk/press/20050628openaccess.asp>, [accessed 30.06.05] 
Rowland, F., 2005. Re: A Prophylactic Against the Edentation of the RCUK Policy Proposal. American Scientist Open Access Forum, SIGMAXI.ORG, 5 July 2005, 13:46:09 +0100 GMT.

Rowland, F. et al., 2004. Delivery, management, and access model for e-prints and open access journals. Serials Review [online], 30(4), 298-303.

<http://www.sciencedirect.com/...>, [accessed 27.05.05].

Rowlands, I. et al., 2004. Scholarly communication in the digital environment: what do authors want? London: Centre for Information Behaviour and the Evaluation of Research. <http://ciber.soi.city.ac.uk/ciber-pa-report.pdf>, [accessed 16.06.05].

Schroter, S. et al., 2005. Perceptions of open access publishing: interviews with journal authors. British Medical Journal [online], 330 (7494): 756-759. <http://bmj.bmjjournals.com/cgi/reprint/330/7494/756>, [accessed 16.06.05].

Steele, C., 2003. Digital libraries and repositories. Information Management Report, March, 1-5.

Stevenson, I., 2004. Is open access the new vanity publishing? Learned Publishing [online], 17(2), 83-84. <http://docserver.ingentaconnect.com/...>, [accessed 26.05.05].

Suber, P., 2003. Bethesda Statement on Open Access Publishing. <http://www.earlham.edu/ peters/fos/bethesda.htm>, [accessed 13.06.05].

Suber, P., 2004. The many-copy problem and the many-copy solution. Open Access Now [online], 14(15 March)

<http://biomedcentral.com/openaccess/archive/?page=features\&issue=14>, [accessed 30.06.05].

Swan, A and Brown, S., 2003. Authors and electronic publishing: what authors want from the new technology. Learned Publishing [online], 16(1), 28-33. $<$ http://ceres.ingentaconnect.com/...>, [accessed 27.05.05]. 
Swan, A. and Brown, S., 2004. Authors and open access publishing. Learned Publishing [online], 17(3), 219-224. <http://docserver.ingentaconnect.com/...>, [accessed 27.05.05].

Swan, A. and Brown, S., 2005. Open access self-archiving: an author study. Truro: Key Perspectives Limited. Available online at:

$<$ http://www.jisc.ac.uk/uploaded_documents/Open\%20Access\%20Self\%20Archi ving-an\%20author\%20study.pdf>, [accessed 10.06.05].

Swan, A. et al., 2005a. Developing a model for e-prints and open access journal content in UK further and higher education. Learned Publishing [online], 18(1), 25-40. <http://docserver.ingentaconnect.com/...> , [accessed 27.05.05].

Swan, A. et al., 2005b. Delivery, management and access model for e-prints and open access journals within further and higher education.

<http://eprints.ecs.soton.ac.uk/11001/01/E-prints_delivery_model.pdf>, [accessed 30.06.05].

Velterop, J., 2005. Re: Complementary or competitive. American Scientist Open Access Forum, SIGMAXI.ORG, 25 Aug 2005 16:38:40 +0200 GMT.

Ware, M., 2004. Institutional repositories and scholarly publishing. Learned Publishing [online], 17(2), 115-124. <http://docserver.ingentaconnect.com/...>, [accessed 26.05.05].

Yeates, R., 2003. Institutional repositories. VINE: The Journal of Information and Knowledge Management Systems [online], 33(2), 96-100.

<http://hermia.emeraldinsight.com/...>, [accessed 26.05.05]. 


\section{Appendix 1. Emails to prospective respondents}

\section{A1.1 Email to IR managers}

Subject: Research students and Institutional Repositories.

I see from ___ [name of website] that you are the [role of contact]

for your institution's repository. I wonder if you could help me?

I am currently a student in the Dept of Information Science at Loughborough University. For my Masters' dissertation I am investigating the role and value of an institutional repository to research students. The hope is that this will inform the team currently undertaking a feasibility study for a Loughborough repository.

My questions to you are:

1. What (if any) use do research students make of your repository (either as authors or as readers)?

2. Have you promoted the repository specifically to research students?

3. Do you think there is a place for research student output in your repository?

I would really appreciate your comments and would be happy to discuss this with you further if you wish. I can of course send you a copy of my executive summary when my work is complete.

My supervisor here at Loughborough is Professor Cliff McKnight (C.Mcknight@lboro.ac.uk). Please feel free to contact him if you have any concerns about this email.

Thank you.

For managers of ETD repositories, the questions were rephrased to:

1. How much use do research students make of your repository (either as authors or as readers)?

2. How have you promoted the repository to research students?

3. Is your repository only for theses or do you think there is a place for other research student output in your repository? 


\section{A1.2 Email to research students}

\section{Subject: The Loughborough Repository - can you help?}

I see from your departmental website that you are a research student in the department of I wonder if you could help me?

I am currently a Masters student in the Dept of Information Science. For my dissertation I am investigating the role and value of a possible digital 'institutional repository' to research students.

My work ties in with a major project which has just begun within the University to investigate the feasibility of a digital repository here at Loughborough. The hope is, that like the repositories at Nottingham, Bristol, Oxford, Cambridge and other major universities, the Loughborough Repository will store the research output of university members in one accessible place, and make this available, via search engines, to the outside world.

Most other institutions do not appear to have considered the requirements of research students when planning their repositories. As Loughborough is still at an early stage in this process, it seems that this might be a good time to find out the views of research students. I would like to be able to then make some appropriate recommendations to the project managers.

Would you have about 30 minutes to spare over the next couple of weeks in which we could talk about your views on the proposed Loughborough Repository? I will not assume any prior knowledge and will gladly answer any questions you may have. I am happy to meet you at a time and place of your choosing.

If you are willing to talk to me l'd be grateful if you could give me a choice of two or three dates and time slots when you are free. I am available from Thursday 7th July to Thursday $21^{\text {st }}$ July, excluding Wednesdays.

Thank you for your help. 


\section{Appendix 2. Research Student Interview Schedule}

\section{Department:}

\section{PART 1. INTRODUCTION}

Explain the purpose of this interview:

- Research for Masters project

- Context: start of feasibility study for proposed Loughborough Repository

- Wish to establish the views of research students so they can be submitted to those responsible for planning the repository

- Reassure respondent that anything they are unfamiliar with will be explained

- Conform to requirements of ethical checklist (right to withdraw etc)

First I'm going to ask you some questions about your current research practices...

Q1.1 What is your general area of research?

Q1.2 Can you tell me something about how you go about finding information for your research? For example, where would you look and what resources would you use?

\begin{tabular}{|l|l|l|}
\hline & & Specify \\
\hline Library OPAC & & \\
\hline Library website & & \\
\hline Metalib & & \\
\hline Library (printed resources) & & \\
\hline Other printed resources & & \\
\hline Online - internet - search engines & & \\
\hline Online - internet - subject gateways & & \\
\hline Online - subscription databases & & \\
\hline Online - publishers websites & & \\
\hline Online - open access & & \\
\hline Other online resources & \\
\hline
\end{tabular}


Q1.3. Have you ever made any of your own work publicly available (for example in a journal, on a website (your own or a publisher's) or in departmental publication), either here at Loughborough, or previously?

Q1.3.1. [If Yes] Please tell me something about this. What type of work was it (for example an article, conference paper, book chapter etc) and where did you make it available?

Q1.3.2. [If Yes] Were there any particular reasons why you chose to make your work available where you did?

Q1.4. As a general principle, do you think it is important that you publish your work?

Yes I No

Q1.4.1. [ If Yes] What would be your reasons for publishing your work? Please look at this card and tell me where you stand on each reason.

(Interviewer ticks one box per reason). (after Swan \& Brown 2005, p.23).

\begin{tabular}{|l|l|l|l|l|l|}
\hline Reason for publishing work & $\begin{array}{l}\text { Strongly } \\
(1)\end{array}$ & $\begin{array}{l}\text { Agree } \\
(2)\end{array}$ & $\begin{array}{l}\text { Neutral } \\
(3)\end{array}$ & $\begin{array}{l}\text { Disagree } \\
(4)\end{array}$ & $\begin{array}{l}\text { Strongly e } \\
(5)\end{array}$ \\
\hline To communicate results to your peers & & & & \\
\hline To advance your career & & & & \\
\hline For personal prestige in your field & & & & \\
\hline $\begin{array}{l}\text { To increase your chances of gaining } \\
\text { funding }\end{array}$ & & & & \\
\hline For direct financial reward & & & & \\
\hline Other (please specify) & & & & \\
\hline
\end{tabular}




\section{PART 2. OPEN ACCESS PUBLISHING}

Now we are moving on to talk about a relatively new development in academic publishing - the open access movement. Just to begin with l'd like to be sure we are both talking about the same thing...

Q2.1. Do you know what is meant by 'open access'? Yes I No

Q2.1.1. [If Yes] Could you explain to me what you understand by this?

(If necessary, show card and reach agreement)

Q2.1.2. [If Yes] How did you find out about the open access movement? (after Swan \& Brown 2005, p.48). (Interviewer to tick box)

\begin{tabular}{|l|l|}
\hline Work in a field with established subject based archives & 1 \\
\hline Followed the debate on open access & 2 \\
\hline From information provided by institution or library & 3 \\
\hline From information provided by faculty or department & 4 \\
\hline From academic staff & 5 \\
\hline From fellow students & 6 \\
\hline Other (specify) & 7 \\
\hline
\end{tabular}

Q2.1.3. [If No] Show card with definition of Open Access and explain.

Q2.2. Are you aware of the current debate over the 'crisis' in scholarly publishing? [If Yes] What are your views on this?

Q2.3. Open access publishing generally means making your work available in an open access journal or in a digital repository of some sort. Do you know what is meant by a 'digital repository'? Yes I No

Q2.3.1. [If Yes] Could you explain to me what you understand by this?

(If necessary, show card and reach agreement)

Q2.3.3. [If No] Show card with definition of Digital Repository and explain.

Q2.4. Are you aware that you could deposit your work in a digital repository? 
Q2.6. Are you aware of any specific subject repositories in your field?

Yes / No

Q2.6.1. [If Yes] Which ones are they?

Q2.7. Are you aware of any institutional repositories?

Yes / No

Q2.7.1. [If Yes] Which one(s)?

Q2.8. Before I contacted you, did you know that Loughborough University was just starting a project to investigate the feasibility of an institutional repository?

Yes / No

\section{PART 3. THE LOUGHBOROUGH REPOSITORY - PRACTICALITIES}

To begin with, I would like to assume that you were both willing and able to deposit your work in the Loughborough Repository. In other words, you had been persuaded of the benefits of the repository and any fears you might have had would have been allayed. Under these circumstances...

Q3.1 What type of work do you think you would want to deposit? Please look at this card and tell me which types you would deposit. (Interviewer ticks multiple boxes). (after Swan \& Brown 2005, p.23).

\begin{tabular}{|l|l|l|l|}
\hline & Yes & No & $\begin{array}{l}\text { Don't } \\
\text { know } \\
(3)\end{array}$ \\
\hline Thesis (complete) & $(1)$ & $(2)$ & \\
\hline Thesis (part) - Literature review & & & \\
\hline Thesis (part) - Methodology & & & \\
\hline Thesis (part) - Results & & \\
\hline Thesis (part) - Discussion & & \\
\hline Thesis (part) - Data sets & & & \\
\hline Research report & & \\
\hline Co-authored work & & & \\
\hline Preprint (research article before peer review) & & \\
\hline Postprint (peer-reviewed research paper) & & \\
\hline Conference paper & & & \\
\hline Presentation & & & \\
\hline Departmental paper (e.g. seminar paper) & & \\
\hline Book & & & \\
\hline Dataset & & \\
\hline Other (specify) & & \\
\hline
\end{tabular}


Q3.2 Which file formats do you generally use and therefore might wish to deposit?

It would be helpful to know exactly which formats you use.

(Interviewer ticks multiple boxes). (after Swan \& Brown 2005, p.23).

\begin{tabular}{|l|l|l|l|}
\hline & $\begin{array}{l}\text { Yes } \\
(1)\end{array}$ & $\begin{array}{l}\text { No } \\
(2)\end{array}$ & $\begin{array}{l}\text { Don't know } \\
(3)\end{array}$ \\
\hline HTML & & & \\
\hline XML & & & \\
\hline PDF & & & \\
\hline Word processed document (eg MS Word) & & & \\
\hline Rich text format (.RTF) & & \\
\hline Desktop publishing or typesetting (Postscript, LaTeX) & & \\
\hline Technical drawings & & \\
\hline Image (.gif, .jpg, .tif etc) & & \\
\hline ASCII & & & \\
\hline Presentation (eg MS Powerpoint) & & & \\
\hline Spreadsheet (eg. MS Excel) & & & \\
\hline Database (eg. MS Access) & & & \\
\hline Sound (.wav, .mp3,.aiff) & & & \\
\hline Video (mpeg, DVI, Quicktime) & & & \\
\hline Other (please specify) & & \\
\hline
\end{tabular}

Q3.3 Thinking of yourself now as a user of information, what type of work do you think you would wish to find on the Loughborough Repository?

Please look at this card and tell me which types you would like to find there.

\begin{tabular}{|l|l|l|l|}
\hline & $\begin{array}{l}\text { Yes } \\
(1)\end{array}$ & $\begin{array}{l}\text { No } \\
(2)\end{array}$ & $\begin{array}{l}\text { Don't mind } \\
\text { (3) }\end{array}$ \\
\hline Theses (complete) & & & \\
\hline Theses (part) & & & \\
\hline Research reports & & & \\
\hline Preprints (research article before peer review) & & & \\
\hline Postprints (peer-reviewed research paper) & & & \\
\hline Conference papers & & & \\
\hline Presentations & & & \\
\hline Departmental papers (e.g. seminar papers) & & & \\
\hline Technical reports & & & \\
\hline Working papers & & & \\
\hline Discussion papers & & & \\
\hline Teaching materials & & & \\
\hline Data sets & & & \\
\hline Software & & & \\
\hline Books & & & \\
\hline Book chapters & & & \\
\hline Training manuals & & \\
\hline Video files & & \\
\hline Sound files & & \\
\hline Other (specify) & & \\
\hline
\end{tabular}


Although it is to be hoped that the process of depositing material would be made as straightforward and quick as possible, there will undoubtedly be certain tasks involved.

Q3.4 Who do you think should be responsible for the following tasks? Please look at this card and tell me who you think should do each task.. (Interviewer ticks one box per task). (after Swan \& Brown 2005, p.23).

\begin{tabular}{|l|l|l|}
\hline & $\begin{array}{c}\text { You } \\
(1)\end{array}$ & $\begin{array}{c}\text { Repository } \\
\text { Administrators } \\
\text { (2) }\end{array}$ \\
\hline $\begin{array}{l}\text { Converting source material to appropriate } \\
\text { format for deposit }\end{array}$ & & \\
\hline Providing key words & & \\
\hline $\begin{array}{l}\text { Providing an abstract (or descriptive summary } \\
\text { of content) }\end{array}$ & & \\
\hline $\begin{array}{l}\text { Providing web links to associated material (e.g. } \\
\text { referenced articles, data sets etc) }\end{array}$ & \\
\hline \begin{tabular}{l} 
Putting the work onto the repository \\
\hline $\begin{array}{l}\text { Entering appropriate descriptive information } \\
\text { (author, title, date, key words, abstract) }\end{array}$
\end{tabular} & \\
\hline $\begin{array}{l}\text { Confirming intellectual property rights } \\
\text { Converting files to the latest version of software } \\
\text { or hardware (e.g. to new version of Microsoft } \\
\text { WORD) after the work has been deposited }\end{array}$ & & \\
\hline Decision to delete work & & \\
\hline Deleting work & & \\
\hline
\end{tabular}

Some organisations, such as the House of Commons Select Committee on Science and Technology, and more recently, the Research Councils UK, have recommended that research awarding bodies should mandate their funded researchers to deposit their articles in an open access repository.

Q3.5 If the university or your research funder required you to deposit copies of your articles in the Loughborough Repository, what would be your reaction? (after Swan \& Brown 2005, p.63).

\begin{tabular}{|l|l|}
\hline Would comply willingly & 1 \\
\hline Would comply reluctantly & 2 \\
\hline Would not comply & 3 \\
\hline
\end{tabular}




\section{PART 4. THE LOUGHBOROUGH REPOSITORY - ATTITUDES}

In this final section I would like to investigate your views about the Loughborough Repository. I will show you a series of statements - some are facts, some are opinions, and others are even misconceptions.

[continued on next page] 
I would like you to indicate whether you agree or disagree with each statement.

(4.1 \& 4.2 Two sets of cards are presented together in random order, the research student puts them into one of two piles: 'Agree' and 'Disagree')

4.1 I would deposit my work in the Loughborough Repository ...

1. Because I support the principle of open access

2. Because I wish to be involved with innovative technology

3. Because I would like to be able to make my work available to other students

4. Because I would like to be able to make my work available to others in the university

5. Because I would like to be able to make my work available to myself from anywhere

6. Because I would like to be able to share material with my research collaborators

7. Because I would like to get feedback or commentary from others

8. Because it would enable me to publish my work very quickly

9. If I was encouraged to do so by my supervisor

10. If I was encouraged to do so by my department

11. If I was encouraged to do so by my fellow students

12. If I was encouraged to do so by my research funders

13. If I was encouraged to do so by my co-authors

14. If I was encouraged to do so by library staff

15. Because I like the idea of being able to publish supplementary material such as data sets, video clips or sound files.

16. Because I would like to take advantage of added services such as download counts and cross-searching

17. Because I like the idea of my work being permanently available

18. Because I would like to maintain multiple versions of my work

19. Because I would like someone else to take responsibility for preserving my work

20. Because I would find it easier to publish in the Loughborough Repository than to publish anywhere else

21. Because I would use it as practice for getting published elsewhere

22. Because it would be helpful for collecting and organising my work

23. Because it would be helpful for gathering information about my work for career purposes

24. Because it might help me establish priority or prove ownership of my ideas

25. So I could retain the intellectual property rights for my work

26. If I was informed of the benefits of doing so

27. If I was given training on how to do so

28. If I was provided with step-by-step instructions online

29. If there was a nominated Loughborough Repository representative in my department that I could go to for advice

30. If I was following the example of many others

31. If I was paid to do so

32. I believe it is a good way of disseminating my work to the research community and beyond




4.2 I would be unhappy about depositing my work in the Loughborough Repository because...

1. I perceive that few people would see my work there

2. I perceive that the readership of the repository would be too broad and not targeted to my field of work

3. I perceive that the repository would have low prestige

4. I do not want to put my work with work that has not been peer-reviewed

5. I would not want my work to be subject to a quality control process

6. I would not want my work to be deposited with work from other disciplines

7. I am concerned that the content of the repository is too ephemeral

8. I would prefer to deposit it in another repository (such as a subject repository)

9. I would prefer to make my work available only on my personal website

10. I would prefer to make my work available only on my departmental website

11. I am concerned about other publishers owning the copyright of previously published material

12. My work is confidential

13. I am concerned that others might copy my work without my permission

14. I am concerned that others might alter my work without my permission

15. I am concerned about plagiarism

16. I am concerned that if I deposit my work in the Loughborough Repository I may not be able to publish it elsewhere later

17. I am afraid it might take too much time

18. I am concerned that I do not have the necessary technical skills

19. I am concerned about the long term feasibility of the repository

20. I am concerned that my work might not be preserved in the long term

21. I might want to change or delete my work

22. I am concerned about the 'newness' and initially small scale of the repository

23. I am concerned about the effect of open access repositories on journal publishers

24. I am concerned about the effect of open access repositories on Learned Societies and Associations

25. I am concerned that my images and graphics will require too much storage capacity and download time

26. I am concerned that the University might expect me to pay to do it

27. I am concerned that the University might do something with my work without my permission

28. I am concerned about what would happen to my work if I moved to another institution.




Interviewer sorts the 'agree' pile into motivations (cream) and deterrents (pale orange). The 'disagree' pile is removed.

Now please will you select from the 'Agree' piles about five statements (of each colour) which you think are most important to you, or would be most likely to motivate or deter you from depositing your work in the Loughborough Repository.

Now please place these in rank order.

\section{PART 5. DEBRIEF}

Q4.3 On balance, do you think you would deposit any of your work in the Loughborough Repository?

Thank you for your help.

Have you any further comments or questions? 